\title{
In Vivo, In Vitro, and Computational Analysis of Dendritic Calcium Currents in Thalamic Reticular Neurons
}

\author{
Alain Destexhe, ${ }^{1,2}$ Diego Contreras, ${ }^{2}$ Mircea Steriade, ${ }^{2}$ Terrence J. Sejnowski, ${ }^{1,3}$ and John R. Huguenard 4 \\ 1The Howard Hughes Medical Institute, The Salk Institute for Biological Studies, Computational Neurobiology Laboratory, \\ La Jolla, California 92037, 2Laboratoire de Neurophysiologie, Faculte de Medecine, Universite Laval, Quebec, Canada \\ G1K 7P4, ${ }^{3}$ Department of Biology, University of California, San Diego, La Jolla, California 92037, and ${ }^{4}$ Department of \\ Neurology and Neurological Sciences, Stanford University Medical Center, Stanford, California 94305
}

Thalamic reticular (RE) neurons are involved in the genesis of synchronized thalamocortical oscillations, which depend in part on their complex bursting properties. We have investigated the intrinsic properties of RE cells using computational models based on morphological and electrophysiological data. Simulations of a reconstructed $\mathrm{RE}$ cell were compared directly with recordings from the same cell to obtain precise values for the passive parameters. In a first series of experiments, the lowthreshold calcium current $\left(I_{T s}\right)$ was studied via voltage clamp in acutely dissociated RE cells that lack most of their dendrites. Simulations based on a cell with truncated dendrites and Hodgkin-Huxley kinetics reproduced these recordings with a relatively low density of $I_{T s}$. In a second series of experiments, voltage-clamp recordings obtained in intact $R E$ cells in slices showed a higher amplitude and slower kinetics of $I_{T S}$. These properties could be reproduced from the reconstructed cell model assuming higher densities of $I / s$ in distal dendrites. In a third series of experiments, current-clamp recordings were obtained in RE cells in vivo. The marked differences with in vitro recordings could be reconciled by simulating synaptic bombardment in the dendrites of RE cells, but only if they contained high distal densities of $I_{T s}$, In addition, simpler models with as few as three compartments could reproduce the same behavior assuming dendritic $I_{T s}$. These models and experiments show how intrinsic bursting properties of RE cells, as recorded in vivo and in vitro, may be explained by dendritic calcium currents.

Key words: sleep; synchronized oscillations; voltage clamp; bursting; intrinsic electrophysiological properties; multicompartment models; low-threshold calcium current
Thalamic reticular (RE) neurons are strategically located to receive collaterals from most thalamocortical and corticothalamic fibers. RE neurons typically fire bursts of action potentials during synchronized sleep or anesthesia (Steriade et al., 1986), and a low-threshold $\mathrm{Ca}^{2+}$ current, $I_{T s}$, underlies the production of these bursts (Llinás and Geijo-Barrientos, 1988; Huguenard and Prince, 1992; Bal and McCormick, 1993). Together with similar bursting properties in thalamocortical (TC) relay cells, the TC-RE reciprocal interaction is central to the genesis of various types of synchronized oscillations and epileptic behavior (Steriade et al., 1993; von Krosigk et al., 1993; Huguenard and Prince, 1994; Warren et al., 1994).

The bursts in RE cells differ from those in TC cells in several ways. First, RE cells typically produce broad bursts which dcvelop morc slowly than in TC cells (Mulle et al, 1986; Steriade et al., 1986; Llinás and Geijo-Barrientos, 1988). This is corroborated by the slower activation and inactivation kinetics of the T-current in these neurons (Huguenard and Prince, 1992). Second, relatively strong current pulses need to be injected to evoke bursts in RE cells compared with TC cells (Mulle et al., 1986; Bal and McCormick, 1993; Contreras et al., 1993), suggesting that $I_{T s}$ is located in the dendrites. Third, the pattern of sodium spikes within a burst typically increases then

Received May 24, 1995; revised Sept. 15, 1995; accepted Sept. 20, 1995.

This research was supported by The Howard Hughes Medical Institute, National Institutes of Health (NINDS Grant NS06477), and The Mcdical Rescarch Council of Canada. We acknowledge Dr. D. Amaral for the use of his neuron tracing system. Correspondence should be addressed to Dr. A. Destexhe, Department of Physiology, Laval University School of Medicine, Quebec, Canada G1K 7P4.

Copyright (c) 1995 Society for Neuroscience 0270-6474/95/160169-17\$05.00/0 decreases in frequency (Domich et al., 1986; Avanzini et al., 1989; Contreras et al., 1993; Huguenard and Prince, 1994; Bal et al., 1995). This accelerando-decelerando pattern is routinely used as a criterion to recognize RE cells from extracellular recordings (Steriade et al., 1986). Fourth, in RE cells recorded in vivo, the burst develops gradually (Contreras et al, 1993), unlike the all-or-none properties seen in TC cells

Computational studies of RE cells thus far have been based on single-compartment models containing $I_{T s}$ as well as other currents identified in RE cells. Some of these models successfully account for the rhythmicity generated within the RE nucleus (Destexhe and Babloyantz, 1992; Wang and Rinzel, 1993; Destexhe et al., 1994a; Golomb et al., 1994; Wallenstein, 1994) and the rhythmicity occurring from the interaction between TC and RE cells (Destexhe et al., 1993), but none of them accurately reproduce all of the properties enumerated above.

The primary hypothesis tested in this paper, using computational models combined with in vivo and in vitro intracellular recordings of $\mathrm{RE}$ cells, was that the majority of the T-current arises in the dendrites, as proposed by Mulle et al. (1986). Dendritic calcium currents already have been used to model bursts of action potentials in hippocampal (Traub et al., 1991) and neocortical pyramidal cells (Traub, 1979; Rhodes and Gray, 1994), but these have not been constrained directly by recordings from the same reconstructed cells. Based on voltage-clamp recordings of RE cells with and without dendrites, and morphologically accurate models of these cells, we show how dendritic $I_{T s}$ can account for all voltage-clamp data. We also show that sustained synaptic currents in the dendrites can simulate the properties of RE cells 
as seen from in vivo recordings, only if the major portion of $I_{T S}$ is dendritic.

Some of the results of the present paper appeared as an abstract (Sejnowski et al., 1995).

\section{MATERIALS AND METHODS}

We focus here on neurons from the somatosensory sector of the thalamic reticular nucleus. All in vitro recordings were obtained from RE neurons in young rats (P8-P15), using either intact slice preparation or acutely dissociated cells. Details of the methods used were described by Huguenard and Prince $(1992,1994)$. In vivo recordings were performed in the somatosensory and more rostral sectors of the RE nucleus in adult cats anesthetized with pentobarbital or urethane. The methods were described in detail by Contreras et al. (1993).

An RE neuron was recorded in intact slice preparation (reticular sector of the ventrobasal thalamus in rat) and stained with biocytin. The cell was shown in Figure 1 of Huguenard and Prince (1992). We reconstructed the morphology of the cell from serial sections of $80 \mu \mathrm{m}$, using a computerized tracing system (Eutectic Electronics, Raleigh, NC) kindly provided by Prof. D. Amaral (University of California, Davis). With the $100 \times$ objective used, and correction for tissue shrinkage, the theoretical accuracy with which dendritic diameters can be measured was $0.1 \mu \mathrm{m}$. The neuron traced is shown in Figure $1 A$.

There were four primary dendrites, having a total length of $3785 \mu \mathrm{m}$; the total membrane area of the cell was $15,115.5 \mu \mathrm{m}^{2}$, including $1760 \mu \mathrm{m}^{2}$ for the soma, which was $\sim 20-25 \mu \mathrm{m}$ in diameter. The dendritic arborizations tended to spread in planes parallel to the long axis of the nucleus, as described previously by Ramon y Cajal (1909).

The morphology of the RE cell was incorporated into NEURON, which can simulate the cable geometry from the three-dimensional coordinates provided by the tracing of the neuron (for more details, see

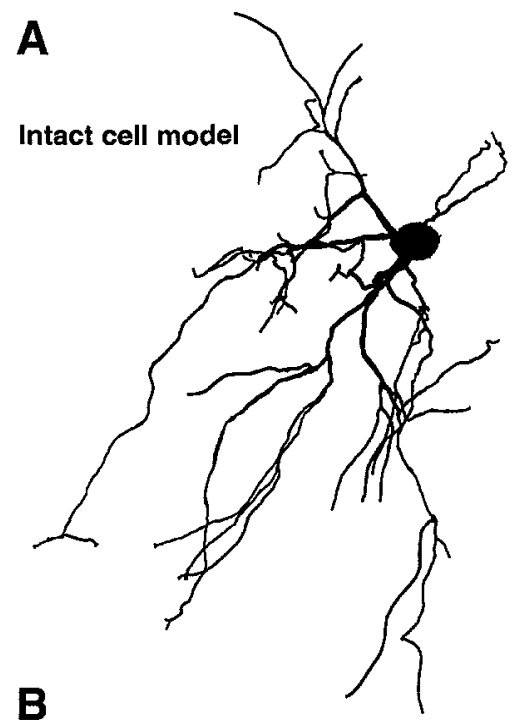

Dissociated cell model

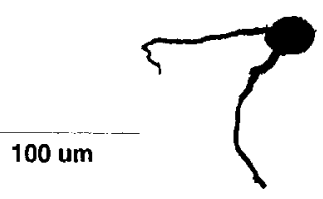

Figure 1. A, Reconstructed RE cell from the ventrobasal sector of the thalamic reticular nucleus of the rat. The cell was stained with biocytin during recordings in intact slice preparation (Huguenard and Prince, 1992); reconstructed using a computerized tracing system and incorporated into the NEURON simulator. Models with either 80 or 230 compartments were used. $B$, Model of a dissociated RE cell, obtained by removing most of the dendrites from the intact cell.
Hines, 1989). The two equivalent cable models studied had either 80 or 230 compartments and gave identical results.

In acutely dissociated cells, most of the dendritic arborizations were removed by the dissociation procedure (see Fig. 2 of Huguenard and Prince, 1992). Simulations of acutely dissociated RE cells used a cable geometry obtained by truncating the dendrites of the original cell (Fig. $1 B$ ). The model shown in Figure $1 B$ had only the soma and the most proximal parts of dendrites ( 8 compartments), with a total membrane area of $3639 \mu \mathrm{m}^{2}$. The input capacitance of this model was similar to, but slightly larger than, that measured from dissociated RE cells (Huguenard and Prince, 1992).

A procedure was developed, based on a simplex algorithm (Press et al., 1986), for fitting the simulations to experimental data to find optimal values for passive parameters. At each iteration of the simplex algorithm, the model was run and the squared error between the experimental recording and the model was minimized. This procedure was repeated from different initial conditions to avoid unstable values of parameters. The values of passive parameters were considered uniform and were consistent with the values estimated from the recordings. Approximately 150-450 iterations were required to converge to a minimum error.

For the cell shown in Figure $1 A$, voltage-clamp recordings were obtained in the same cell. We used these recordings to estimate the passive parameters by fitting the model to the data (Fig. $2 A$ ). It has been shown that when the cable geometry of the cell is known, this procedure should lead to a unique set of parameter values if they are uniform (Rall et al., 1992), which was the case here. A direct fit to current-clamp recording was not performed here, because the model included only a subset of the currents present in these cells.

Voltage-dependent conductances were modeled using a HodgkinHuxley type of kinetic model (Hodgkin and Huxley, 1952). The $\mathrm{Na}^{+}$and $\mathrm{K}^{+}$currents responsible for fast action potentials were inserted in the soma, and their kinetics was taken from a model of hippocampal pyramidal cells (Traub and Miles, 1991), assuming a resting potential of -67 $\mathrm{mV}$ in their equations, maximal conductances of $\bar{g}_{\mathrm{Na}}=100 \mathrm{mS} / \mathrm{cm}^{2}$ and $\bar{g}_{\mathrm{K}}=80 \mathrm{mS} / \mathrm{cm}^{2}$, and reversal potentials of $E_{\mathrm{Na}}=50 \mathrm{mV}$ and $E_{\mathrm{K}}=$ $-100 \mathrm{mV}$.

The kinetics of activation and inactivation of $I_{T s}$ in RE cells, as well as the activation curves of $I_{T s}$, obtained from voltage-clamp recordings in acutely dissociated RE cells (Huguenard and Prince, 1992), were:

$$
\begin{gathered}
I_{T s}=\bar{g}_{\mathrm{Ca}} m^{2} h\left(V-E_{\mathrm{Ca}}\right) \\
\dot{m}=-\frac{1}{\tau_{m}(V)}\left(m-m_{\infty}(V)\right) \\
\dot{h}=-\frac{1}{\tau_{h}(V)}\left(h-h_{\infty}(V)\right),
\end{gathered}
$$

where $\bar{g}_{\mathrm{Ca}}$ (in $\mathrm{mS} / \mathrm{cm}^{2}$ ) is the maximum value of the conductance of the $\mathrm{Ca}^{2+}$ current, $E_{\mathrm{Ca}}$ is the $\mathrm{Ca}^{2+}$ reversal potential, given by the Nernst relation (see below), and $m$ and $h$ are the activation and inactivation variables, respectively. The expressions for steady-state activation and inactivation functions obtained were (Huguenard and Prince, 1992):

$$
\begin{gathered}
m_{\infty}(V)=1 /(1+\exp [-(V+52) / 7.4]) \\
h_{\infty}(V)=1 /(1+\exp [(V+80) / 5]),
\end{gathered}
$$

and the voltage-dependent time constants were:

$$
\begin{gathered}
\tau_{m}(V)=1+0.33 /(\exp [(V+27) / 10]+\exp [-(V+102) / 15]) \\
\tau_{h}(V)=28.3+0.33 /(\exp [(V+48) / 4]+\exp [-(V+407) / 50])
\end{gathered}
$$

as obtained from fitting the time constants measured from the same experiments (see Results). These values correspond to a temperature of $36^{\circ} \mathrm{C}$, assuming $Q_{10}$ values of 2.5 and an extracellular $\mathrm{Ca}^{2+}$ concentration of $2 \mathrm{~mm}$. Different densities of $I_{T s}$ were used for the soma and the dendrites.

Calcium handling was modeled by a first-order system representing $\mathrm{Ca}^{2+}$ pumps and buffers, as in McCormick and Huguenard (1992), with a time constant of decay of $\mathrm{Ca}^{2+}$ of $5 \mathrm{msec}$. The free intracellular $\mathrm{Ca}^{2+}$ concentration at equilibrium was $240 \mathrm{nM}$, and the extracellular $\mathrm{Ca}^{2+}$ concentration was $2 \mathrm{~mm}$, corresponding to a reversal potential of $\sim+120 \mathrm{mV}$. As the intracellular $\mathrm{Ca}^{2+}$ concentration varied, the reversal potential was calculated using the Nernst relation. We compared this assumption with constant field equations, which provides a better 


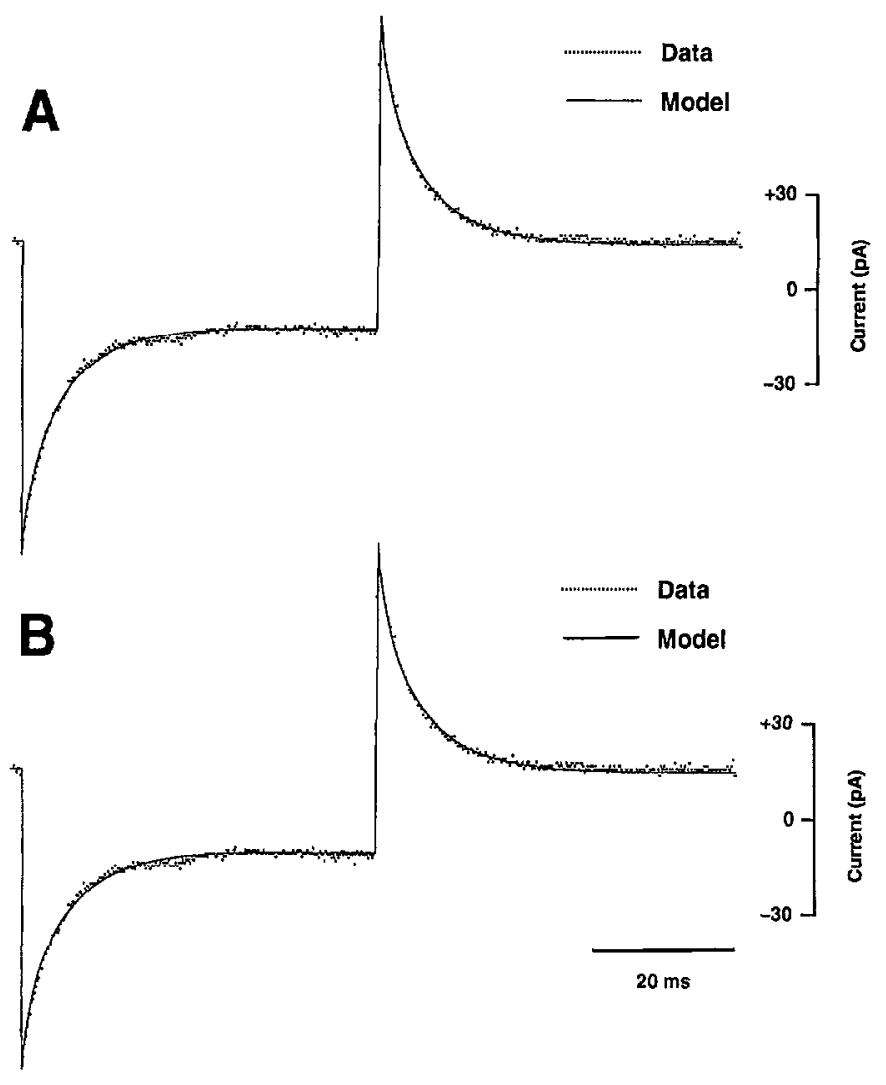

Figure 2. Passive properties of thalamic reticular cells. $A$, Simplex fitting of the multicompartment model to voltage-clamp recordings from the same cell. $(\cdots \cdots)-5 \mathrm{mV}$ voltage-clamp step during $50 \mathrm{msec}$ from a holding potential of $-80 \mathrm{mV}$ (average of 8 traces). ( $\longrightarrow$ ) Best simulation obtained after 450 iterations of the simplex procedure. At each iteration, the same voltage-clamp protocol was simulated in the model cell and the least-square error was computed between the simulation and the data. The procedure was repeated until the model converged to a stable set of values of the parameters from different initial conditions. Eighty or 230 compartments gave identical results. The best parameters were membrane capacitance of $1.01 \pm 0.01 \mu \mathrm{F} / \mathrm{cm}^{2}$, axial resistivity of $260 \pm 30 \Omega / \mathrm{cm}$, leak conductance of $0.05 \pm 0.0001 \mathrm{mS} / \mathrm{cm}^{2}$, and resting potential of $-82.844 \pm$ $0.002 \mathrm{mV}$ (mean values and SD obtained from different initial conditions; ranges of values tested were $0.2-2 \mu \mathrm{F} / \mathrm{cm}^{2}, 50-500 \Omega / \mathrm{cm}, 0.02-0.2 \mathrm{mS} /$ $\mathrm{cm}^{2}$, and -80 to $-85 \mathrm{mV}$, respectively). $B$, Simplex fitting of a simplified multicompartment model to voltage-clamp recordings of an $\mathrm{RE}$ cell. In this case, the same parameters were used as in $A$, and only the dendritic correction factor, $C_{d}$, was fit. The oplimal value obtained was $C_{d}=3.69$ ! 0.01 (range tested $1.5-5$ ). The least-square error was slightly higher $(<1 \%)$ than using the multicompartment model.

model for the nonlinear behavior of $\mathrm{Ca}^{2+}$ currents (Hille, 1992). Simulations of either voltage clamp or current clamp did not reveal any significant difference, even with high densities of $\mathrm{Ca}^{2+}$ channels, suggesting that details of $\mathrm{Ca}^{2+}$ handling had minimal effect on the model.

Finally, simplified models of RE cells with fewer compartments were generated. The method used collapses several dendritic compartments in an "equivalent cylinder," based on the conservation of the axial resistance (Bush and Sejnowski, 1993) rather than conservation of the membrane area (see Rall, 1995). The axial resistance $(R)$ of a cylindrical compartment is the product of its physical length by its axial resistivity $\left(R_{i}\right)$, divided by its section (Rall, 1995). Assuming $R_{i}$ is uniform, several cylindrical compartments of roughly identical physical length are collapsed into an equivalent cylinder. If the cross-sectional area of the equivalent cylinder equals the sum of each individual cross-sectional areas, this is equivalent to summing parallel resistances because $1 / r=\Sigma_{j} 1 / R(j)$, where $R(j)$ is the axial resistance of the collapsed compartments. The radius $(r)$ of the equivalent cylinder is given by

$$
r=\sqrt{\sum_{i} r_{i}^{2}}
$$

where $r_{i}$ is the radius of collapsed compartments. The length is the average of individual lengths. This method has the advantage of providing the correct electrotonic attenuation along the dendritic tree, therefore generating simple models that retain the synaptic and integrative properties of the neuron (Bush and Sejnowski, 1993).

Because the total membrane area is not conserved in this method, the reduced model may not have a correct input resistance. This is compensated for by introducing in each equivalent cylinder a dendritic correction factor $\left(C_{d}\right)$, which rescales the value of conductance $\left(g_{i}\right)$ and membrane capacitance $\left(C_{m}\right)$ in the dendrites such that

$$
g_{i}^{\prime}=C_{d} g_{i}, \quad C_{m}^{\prime}=C_{d} C_{m} .
$$

If $C_{d}$ is estimated correctly, the reduced model will have the correct input resistance and time constant (Bush and Sejnowski, 1993).

Although in principle $C_{d}$ is the ratio between the total surface area of the dendritic segments and their equivalent cylinders (which was $\sim 2.5$ here), a more accurate estimation of this factor was obtained by fitting simulations of the reduced model directly to the voltage-clamp recordings obtained in the cell (Fig. $2 B$ ). The other passive parameters were the same as those obtained from fitting the detailed model to voltage-clamp recordings.

The three compartments of the simplified model had the following lengths $(l)$ and diameters: $l=34.546 \mu \mathrm{m}$ and diameter $=14.075 \mu \mathrm{m}$ for the soma (area of $\left.1527.55 \mu \mathrm{m}^{2}\right) ; l=103.21 \mu \mathrm{m}$ and diameter $=5.56 \mu \mathrm{m}$ for the proximal segment (area of $1803.32 \mu \mathrm{m}^{2}$ ) $; l=190.69 \mu \mathrm{m}$ and diameter $=3.06 \mu \mathrm{m}$ for the distal segment (area of $3636.48 \mu \mathrm{m}^{2}$ ).

The single-compartment model had the same passive properties as determined from voltage-clamp recordings using a model of the detailed morphology and same kinetic parameters for $I_{T s}$ and $\mathrm{Ca}^{2+}$ decay. The densities of currents used in three- and single-compartment models are given in Results.

We used only one anatomically reconstructed RE cell in this study, in addition to morphologically simplified models. The behavior of the detailed and simplified models were nearly identical (see Results), which suggests that the particular details of the morphology of the cell were not important in the context of the present study. The behavior reported in this paper was extremely robust to changes in the values of the parameters, as illustrated by the nearly identical behavior obtained in models with different cable geometries.

All voltage-clamp and current-clamp simulations of the models were done at 24 and $36^{\circ} \mathrm{C}$, respectively.

\section{RESULTS}

We first present in vivo and in vitro intracellular recordings of intrinsic bursts in RE cells and describe how the model was fit to the voltage-clamp data. We next examine current-clamp recordings and investigate the conditions needed to produce bursting behavior consistent with experimental data.

\section{$\mathrm{RE}$ cells in vivo and in vitro}

The typical firing patterns of RE cells in vivo are illustrated in Figure 3. An RE neuron in a conscious animal shows a tonic firing activity (Fig. $3 A$, top). During natural slow-wave sleep, the activity of thalamic cells changes to more rhythmic firing and bursts of action potentials (Steriade et al., 1986). The typical bursts of RE cells during natural sleep show an accelerando-decelerando pattern of action potentials (Fig. 3A, bottom). In intracellular recordings, it was possible to elicit both modes of firing in RE cells, depending on the membrane potential. Depolarizing current pulses from a level of $-68 \mathrm{mV}$ produced tonic firing, whereas the same pulse delivered at more hyperpolarized levels elicited a burst (Fig. $3 B$ ). In this cell, the burst showed a slowly rising phase and was broader than in TC cells, and there was always an accelerando-decelerando pattern of sodium spikes, typical of RE cells in unanesthetized, naturally sleeping animals, as well as in animals 


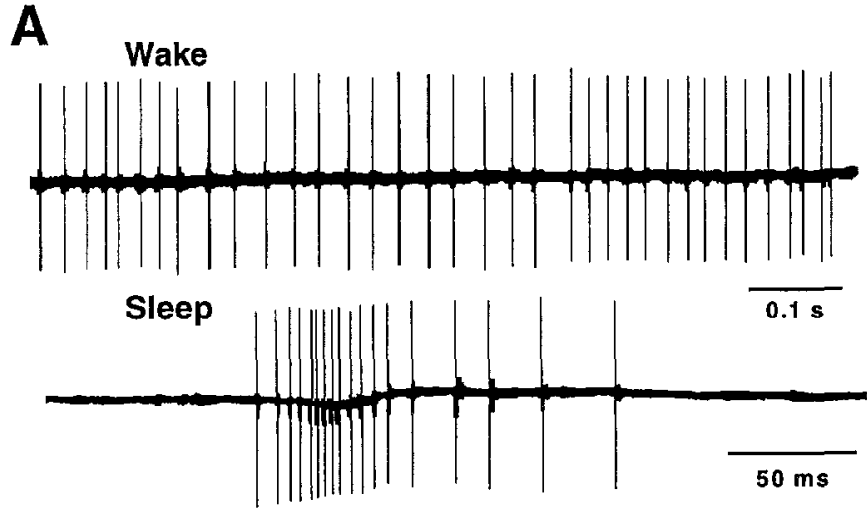

B

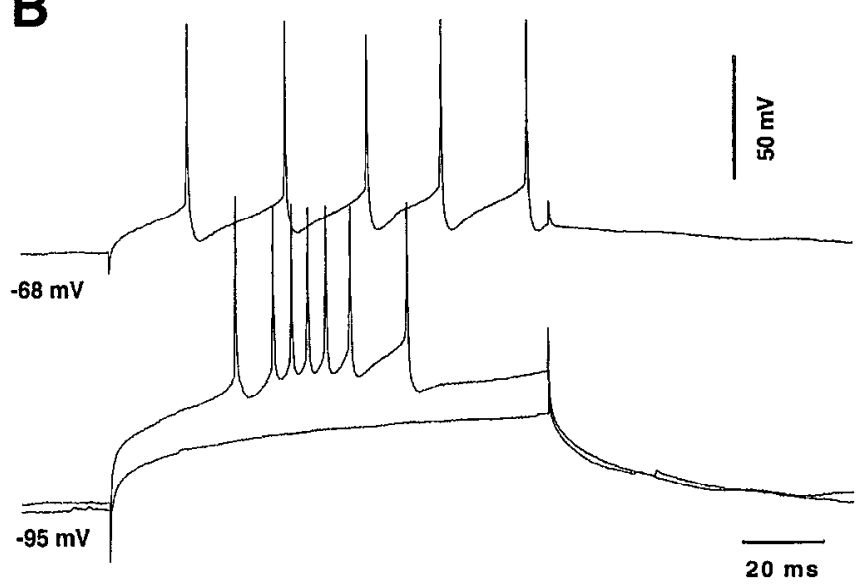

Figure 3. Tonic and bursting firing in thalamic reticular neurons in vivo. $A, \mathrm{RE}$ neuron from the rostrolateral sector was recorded extracellularly in an unanesthetized, chronically implanted cat. The cell discharged tonically during the waking state (Wake), with periods of sustained firing at frequencies between 20 and $60 \mathrm{~Hz}$. During slow-wave sleep (Sleep), the same neuron discharged bursts of action potentials that had a characteristic accelerando-decelerando pattern at the core of the burst, reaching frequencies of up to $400 \mathrm{~Hz}$, followed by a tail of tonic discharge. This pattern is characteristic of RE cells in vivo. B, Intracellular recording of an RE neuron from the rostrolateral sector in a urethane-anesthetized cat. At depolarized membrane potentials $(-68 \mathrm{mV})$, the cell responded to depolarizing square current pulses with tonic discharges, the frequencies of which were proportional to the amount of current injected. Upon DC hyperpolarization $(-95 \mathrm{mV})$, the same pulse gave rise to a passive response. Increasing the amount of injected current triggered bursts of action potentials that had a characteristic accelerando-decelerando pattern with a longer first interval (see also Sleep burst in $A$ ).

under different anesthetics (Domich et al., 1986; Mulle et al., 1986; Steriade et al., 1986; Contreras et al., 1993).

The bursting pattern of RE cells in vivo can be activated gradually (Contreras et al., 1993). In intracellular recordings from three RE cells (Fig. 4), small-amplitude current pulses elicited a passive response, whereas strong current pulses gave rise to a fully developed burst, as in TC cells. However, pulses of intermediate amplitude elicited active, embryonic bursts that did not develop into a full burst response, unlike the characteristic all-or-none behavior observed in TC cells.

In intracellular recordings of RE cells maintained in vitro, the burst also shows a slowly rising phase, a relatively broad structure, and an accelerando-decelerando pattern of sodium spikes, as described in previous studies (Avanzini et al., 1989; Huguenard and Prince, 1994; Bal et al., 1995). However, an important difference between in vivo and in vitro recordings is the all-or-none nature of the burst. In rat thalamic slices, the burst has a clear threshold for activation and its structure is relatively stereotyped (Fig. 5). Both extracellular stimulation (Fig. 5A) and intracellular injection of current pulses (Fig. $5 B$ ) elicit stereotyped bursts with a slow rising phase, an accelerando-decelerando pattern of sodium spikes, and a sharp threshold.

These comparisons reveal important similarities but also clear differences in the electrophysiological properties of RE cells, depending on the preparation, and between RE and TC cells. In the following section, we investigate a detailed morphological model of RE cells and show that their properties can be accounted for by dendritic currents.

\section{Passive properties}

In voltage-clamp mode, short voltage pulses were used to determine the passive properties of the cell. Figure $2 A$ shows the recordings of capacitive transients in the same cell that was filled with biocytin and reconstructed (Fig. 1A). The current transients were not monoexponential and were well fit using two exponentials:

$$
I(t)-A_{1} \exp \left(-t / \tau_{1}\right)+A_{2} \exp \left(-t / \tau_{2}\right),
$$

where $A_{1}=-11 \mathrm{pA}, A_{2}=-57 \mathrm{pA}, \tau_{1}=12.9 \mathrm{msec}$, and $\tau_{2}=4.3$ msec, leading to an electrotonic length of $L=2.7$ (see Rall, 1995). The passive values measured from these capacitive transients were $R_{\mathrm{in}}=170 \mathrm{M} \Omega$ and $C=69 \mathrm{pF}$. The capacitance was measured by dividing the integrated charge by the voltage step. This resulted in a specific capacitance of $\sim 0.5 \mu \mathrm{F} / \mathrm{cm}^{2}$, which is low compared with the typical value of $1 \mu \mathrm{F} / \mathrm{cm}^{2}$ (see Rall et al., 1992). The strong nonisopotentiality of the cell (estimated $L>$ 2.5) together with a high series resistance could explain this discrepancy.

In current clamp, the time course of voltage transients in response to small current pulses was monoexponential with a membrane time constant of $\tau_{m}=23 \pm 1 \mathrm{msec}$. Based on our estimate of $L$ and time constants of capacitive current transients in voltage clamp ( $\mathrm{scc}$ above), the predictcd value of the membrane time constant would be $\tau_{m}=17.3 \mathrm{msec}$ ( $\mathrm{sec}$ Rall, 1995). If this neuron is representative, then the disagreement between these two values indicates that Rall's equivalent cylinder model is inadequate to describe RE neurons.

We also obtained the passive parameters by fitting the simulations of the multicompartment model directly to the recordings obtained in the same cell. The results are shown in Figure $2 A$. From several initial conditions, the model always converged toward similar values, suggesting that only a single set of parameters can match this recording using the geometry of the cell. The input resistance $\left(R_{\text {in }}\right)$ values obtained from the optimal passive parameters were 141-146 M $\Omega$ with axial resistivities between 200 and $300 \Omega / \mathrm{cm}$; the membrane time constant was $20 \mathrm{msec}$, and the total capacitance $(C)$ was $\sim 151 \mathrm{pF}$.

The axial resistivity between 200 and $300 \Omega / \mathrm{cm}$ is high compared with the valucs of $-70 \Omega / \mathrm{cm}$ mcasured in mammalian neurons (Barrett and Crill, 1974). However, the latter is probably an underestimate (see Rall et al., 1992), and our result is consistent with the $100-300 \Omega / \mathrm{cm}$ range for axial resistivity obtained by matching detailed models to experimental data in other cell types (Cauller and Connors, 1992; Stratford et al., 1992; Major et al., 1994; Rapp et al., 1994).

The series resistance was simulated by including a resistance between the cell and the voltage source (voltage-clamp amplifier) and was included as one of the parameters of the fitting procedure. The best fit shown in Figure $2 A$ could be obtained only using rather 
A1

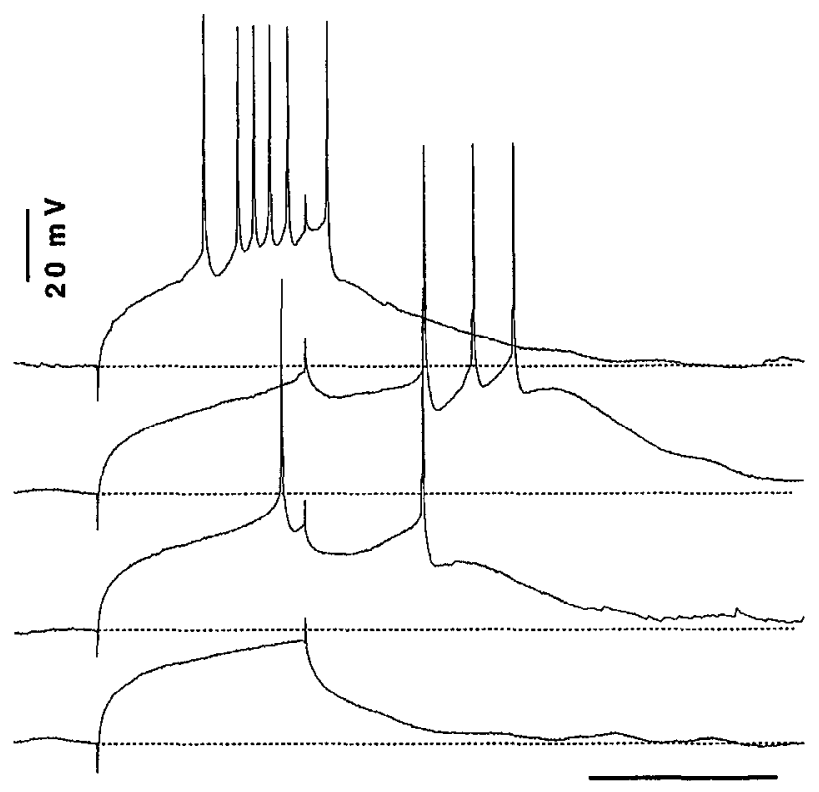

$50 \mathrm{~ms}$
A2

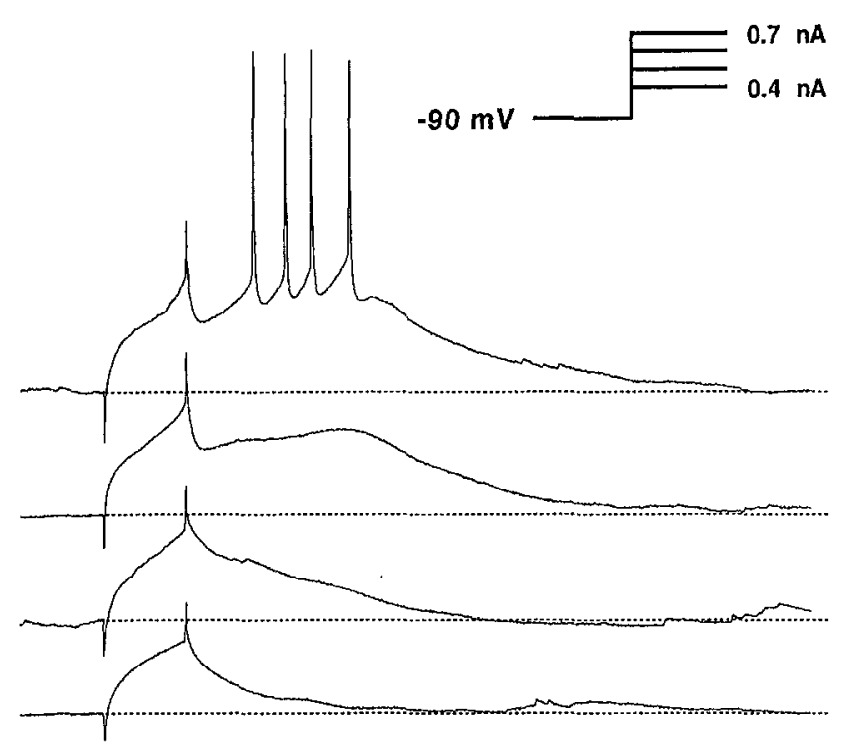

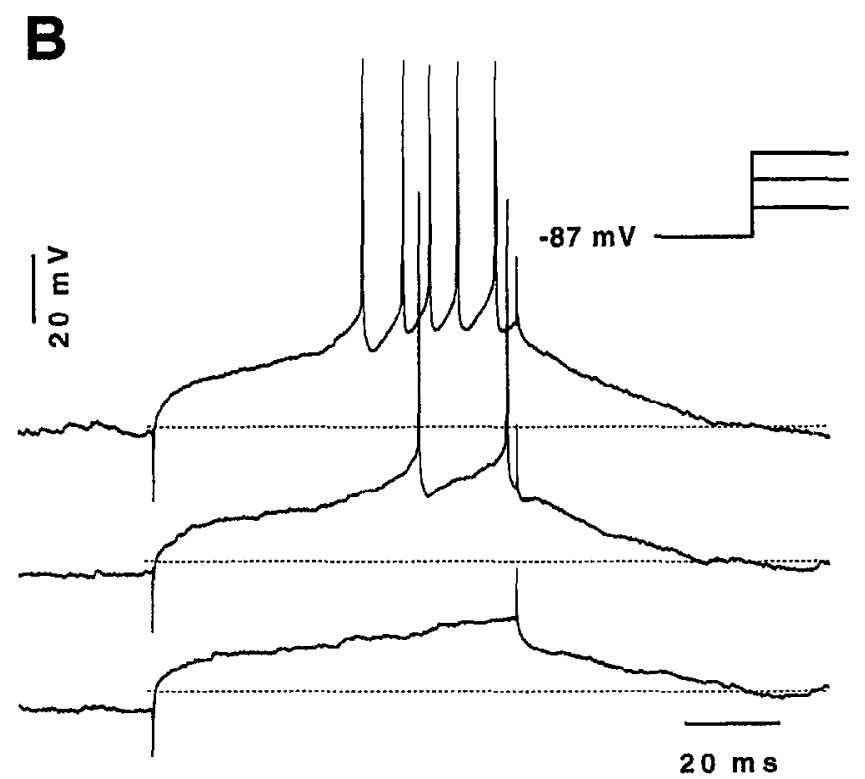

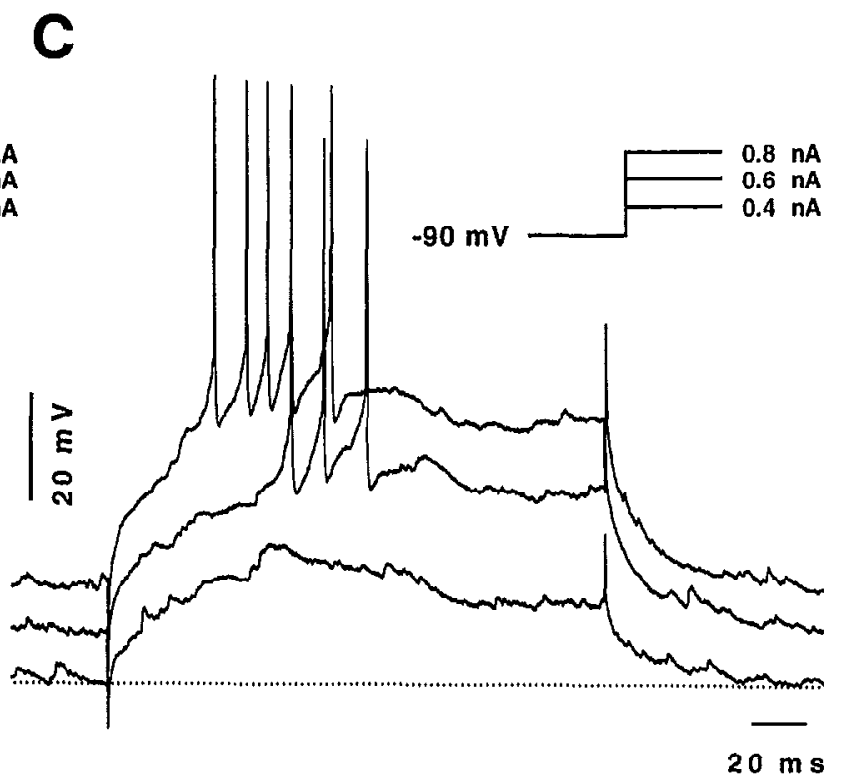

Figure 4. Burst discharges may occur in a graded fashion in RE cells in vivo. Three different cells from the rostrolateral sector of the cat RE nucleus were recorded in vivo under urethane anesthesia. $A$, Injection of square current puises of identical length and increasing amplitudes. Injection of long pulses $(A 1)$ revealed gradually stronger bursts with shorter latencies; pulses of shorter duration $(A 2)$ evoked a burst of strength proportional to the pulse intensity. In both cascs, there was a hypcrpolarizing DC current bringing the membrane potential to $-90 \mathrm{mV}$. $B$, In a different cell, depolarizing current pulses of increasing amplitudes applied at $-87 \mathrm{mV}$ elicit a burst with a growing number of spikes. $C$, The same progressive increase of spike number in a burst shown in a different cell. The pulse protocols and the membrane potential are indicated in the inset.

high series resistance $(20-50 \mathrm{M} \Omega)$, which is consistent with the value measured during the recording. The model fit the nonisopotentiality of the cell as well. The values obtained using this procedure were self-consistent with each other, and they were also in agreement with the passive parameters obtained from RE cells in different preparations (Avanzini et al., 1989; Huguenard and Prince, 1992; Bal and McCormick, 1993; Huguenard and Prince, 1994; Warren et al., 1994). We used these values as the basis for the passive properties of the RE cell in the models presented here.

\section{Localization of the T-current}

The kinetic parameters used for modeling $I_{T s}$ were obtained from voltage-clamp experiments on acutely dissociated RE cells (Huguenard and Prince, 1992). They were best described by a Hodgkin-Huxley formalism with two activation gates and one inactivation gate, for which the voltage-dependent parameters were obtained by fitting exponential expressions to the values determined experimentally (see below). 

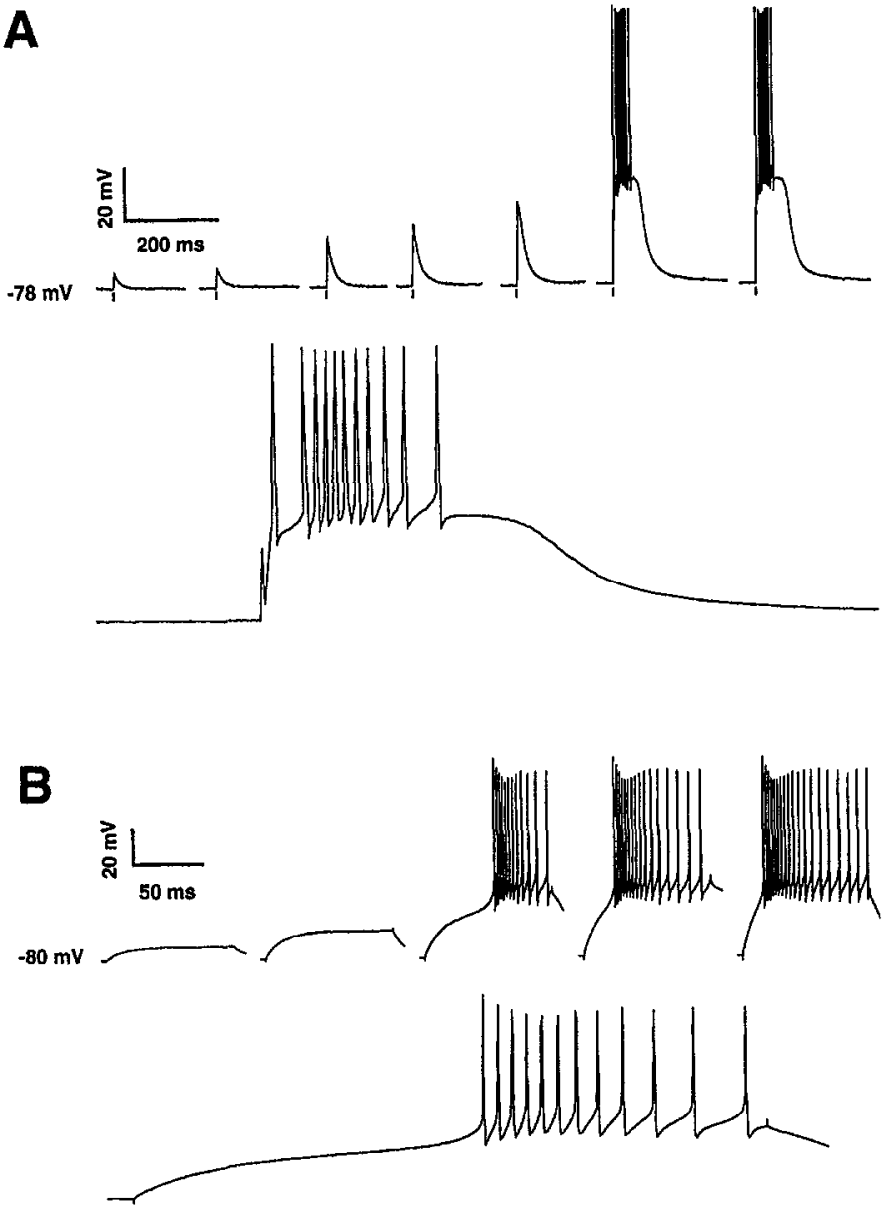

Figure 5. Bursting behavior in intracellularly recorded thalamic reticular cells in vitro. $A$, Bursts obtained from a rat RE cell after extracellular stimulation in an intact slice from the ventrobasal sector of the RE nucleus. Successive stimulations (indicated by bars) were of $100 \mu \mathrm{A}$ intensity and $40,60,80,100,150,200$, and $250 \mu \mathrm{sec}$ duration (from left to right). The burst evoked had a threshold and was all-or-none. The bottom trace indicates a burst with 10 times faster time scale. $B$, Burst obtained after intracellular injection of depolarizing current pulses. The amplitudes of the pulses were $100,200,300,400$, and $500 \mathrm{pA}$, respectively (from left to right). The bursts evoked for the strongest stimuli had a clear threshold for activation, as in thalamocortical cells (Jahnsen and Llinás, 1984); they only differed in the number of spikes produced after the burst. The bottom trace shows the first burst with 5 times faster time scale. In all cases, the bursts of $\mathrm{RE}$ cells had a slow rising phase and sodium spikes within a burst showed a typical accelerando-decelerando pattern. All recordings were at $34^{\circ} \mathrm{C}$.

In acutely dissociated cells, the total $I_{T S}$ current showed a low peak amplitude at $\sim 130 \mathrm{pA}$ (Fig. 6A) (Huguenard and Prince, 1992). Simulations of steady-state activation and inactivation protocols captured the main features of $I_{T s}$ in RE cells, namely (1) a relatively slow inactivation of this current compared with TC cells, (2) a nearly voltage-independent rate of inactivation, and (3) an activation voltage range that is more depolarized than TC cells. Simulated steady-state inactivation of $I_{T s}$ is shown in Figure $6 B$.

The values for the activation $\left(\tau_{m}\right)$ and inactivation $\left(\tau_{h}\right)$ time constants of $I_{T s}$ are shown in Figure $6 C, D$ (see also Fig. $6 C, D$ of Huguenard and Prince, 1992). The best fit of these values assumed a voltage dependence described by biexponential expressions (see Materials and Methods) and is shown in Figure $6 C, D$ (see also Destexhe et al., 1994a).

No change in the kinetics of the T-current was needed to match the voltage-clamp data using the model of the dissociated RE cell shown in Figure $1 B$. Only the density of T-channels had to be adjusted accordingly: for a uniform density, the best fit was obtained with $0.045 \mathrm{mS} / \mathrm{cm}^{2}$ (Fig. 6), independently of the particular details of the morphology chosen to represent dissociated RE cells. However, if $I_{T s}$ was located only in the soma using the geometry of Figure $1 B$, the density needed to match the same recordings was $0.1 \mathrm{mS} / \mathrm{cm}^{2}$.

The values of $I_{T S}$ density from the dissociated cell model were then introduced in the model with an intact cell morphology. Both a uniform density of $0.045 \mathrm{mS} / \mathrm{cm}^{2}$ (Fig. 7, left) and a somatic density of $0.1 \mathrm{mS} / \mathrm{cm}^{2}$, although giving rise to a total current of $\sim 500 \mathrm{pA}$, failed to produce bursts in current-clamp mode. The density of $I_{T s}$ had to be about an order of magnitude higher than these values to elicit bursts: the threshold density for burst generation was $\sim 0.3 \mathrm{mS} / \mathrm{cm}^{2}$ for a uniform density and $\sim 3 \mathrm{mS} / \mathrm{cm}^{2}$ for a somatic density (no $I_{T s}$ in the dendrites). This was the case for bursts generated using either depolarizing or hyperpolarizing current pulses. However, these densities, as well as the current amplitude in voltage clamp, are inconsistent with the recordings from acutcly dissociatcd cells.

One possible way to account for the differences between current clamp in intact cells and voltage clamp in dissociated cells is to assume a high density of $I_{T s}$ in the distal dendrites. We considered a uniform density of $0.045 \mathrm{mS} / \mathrm{cm}^{2}$ in the soma and proximal dendrites, consistent with dissociated cells, and a higher density in distal dendrites (drawn in black in Fig. 7, right). Under these conditions, the minimal distal density for burst generation was $\sim 0.5 \mathrm{mS} / \mathrm{cm}^{2}$. With distally located $I_{T s}\left(0.5-1 \mathrm{mS} / \mathrm{cm}^{2}\right)$, and in the absence of $I_{\mathrm{Na}}$, the amplitude of the low-threshold spike (8-20 $\mathrm{mV}$; data not shown) was consistent with the amplitudes seen experimentally in RE neurons after application of tetrodotoxin (Avanzini et al., 1989; Bal et al., 1993).

\section{Properties of dendritically generated bursts}

A distal localization of the T-current has an important impact on the propertics of burst gencration in RE cells. We studicd here the properties of these bursts assuming the same $I_{T s}$ density as in Figure 7 (left). After a brief pulse of hyperpolarizing current, a broad calcium spike appeared in distal dendrites (Fig. 8), which then elicited sodium spikes in the soma. During the burst, as shown by the successive snapshots and dendritic potential profiles in Figure 8 , the membrane potential remained high in the distal part of the dendritic tree, "feeding" the soma with current. The sodium spikes were generated in the soma and spread only into proximal dendritic segments. Because of the low-pass filtering properties of the dendritic tree, the slow calcium spike has a strong effect in the soma, whereas the backward propagation of the higher frequency sodium spikes is limited. We have not included dendritic sodium currents here, which might affect the dendritic propagation of action potentials (Huguenard et al., 1989; Stuart and Sakmann, 1994; Mainen et al., 1995).

With distal $I_{T s}$, the simulated bursts showed accelerandodecelerando patterns of sodium spikes, typical of RE cells (Figs. 7, 8). The same patterns also persisted after shifting the voltage dependence of $I_{\mathrm{Na}}$ and $I_{\mathrm{K}}$ currents toward more depolarized or hyperpolarized levels (data not shown), suggesting that these currents were not responsible for the accelerando-decelerando, but that the slow rising and decaying phases of the burst were the determining factors.

Further observations support the presence of $I_{T S}$ in the dendrites. First, recordings of intact RE cells in slices show a much higher peak amplitude of the current than in acutely dissociated 

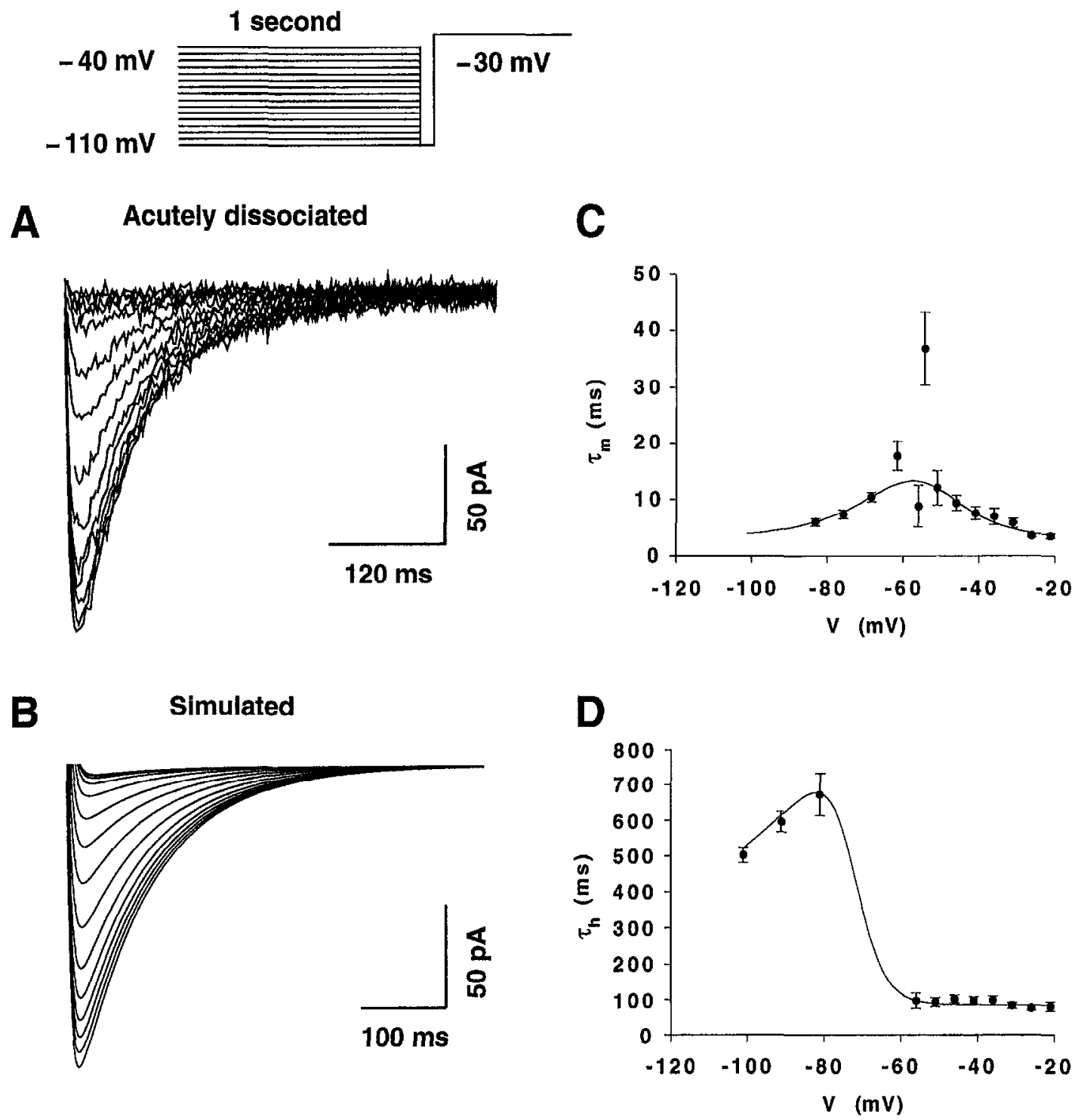

Figure 6. Steady-state inactivation protocol of $I_{r s}$ under voltage clamp. The voltage protocol is depicted at the top: the holding potential was set for 1 $\mathrm{sec}$, followed by a $10 \mathrm{msec}$ hyperpolarization to $-110 \mathrm{mV}$ that preceded the depolarizing command to $-30 \mathrm{mV}$. $A$, Inactivation protocol of the low threshold $\mathrm{Ca}^{2+}$ current $I_{T s}$ in an acutely dissociated rat RE cell (from Huguenard and Prince, 1992). The currents shown were obtained with depolarizations to $-30 \mathrm{mV}$ from different holding potentials. $B$, Simulations of the same inactivation protocols using the cell shown in Figure $1 B$; the density of $I_{T s}$ was estimated as $0.045 \mathrm{mS} / \mathrm{cm}^{2}$ (kinetics from Destexhe et al., 1994a). $I_{T s}$ was located uniformly in the cell, and the density of channels was adjusted to match the amplitude of the currents recorded in dissociated cells. $C$, Fit of the voltage dependence of time constants of activation ( $\left.\tau_{m}\right)$. $D$, Fit of the inactivation time constant $\left(\tau_{h}\right)$. For both $C$ and $D$, the data were from acutely dissociated RE cells (circles are mean values, and vertical bars are SEM) at $24^{\circ} \mathrm{C}$ (Huguenard and Prince, 1992). Solid lines show the best fit obtained using exponential expressions (Destexhe et al., 1994a) (given in Materials and Methods).

cells (see Fig. 9). Although most of the T-channels would be inactivated at the holding potential used $(-71 \mathrm{mV}$ in Fig. $9 B$, left), the current evoked with steps to $-46 \mathrm{mV}$ is much larger than the fully inactivated current obtained with a similar command potential $(-40 \mathrm{mV}$ in Fig. $9 B$, right $)$ in a dissociated neuron. In the model, a high density of $I_{T s}$ in distal dendrites reproduced the higher amplitude of the current seen in the soma ( $\sim 2 \mathrm{nA}$; Fig. 7) compared with dissociated cells $(\sim 150$ pA; Fig. $6 B)$.

Second, voltage-clamp control is extremely difficult to obtain in intact RE cells. Occasionally, with either appropriate voltage protocols to reduce the size of the current or with recordings in cells that had exceptionally small $I_{T S}$ amplitude (as in Fig. 9A), reasonably good clamp was obtained as judged by the lack of notches in the inward current trace. An example from each of these two situations is shown in Figure 9. Simulations of voltage-clamp in intact cells showed that it was virtually impossible to clamp the voltage in the dendrites from a somatic clectrode (Fig. 10). The voltage difference between soma and distal dendrites could be as high as $\sim 80 \mathrm{mV}$ during transients $(60 \mathrm{mV}$ was obtained using constant field equations). This poor voltage control of the dendrites was attributable to the presence of high densities of dendritic $I_{T s}$

Third, the kinetics of $I_{T s}$ was generally slower in intact RE cells compared with acutely dissociated cells (Fig. 9). In Figure 9A, the time course of inactivation was slower in the intact cell; in Figure $9 B$, even though the temperature in the dissociated cell experiment was much cooler than the intact cell experiment ( 23 vs $34^{\circ} \mathrm{C}$ ), the kinetics was similar. The current in the intact neuron 


\section{Uniform density of T-current}

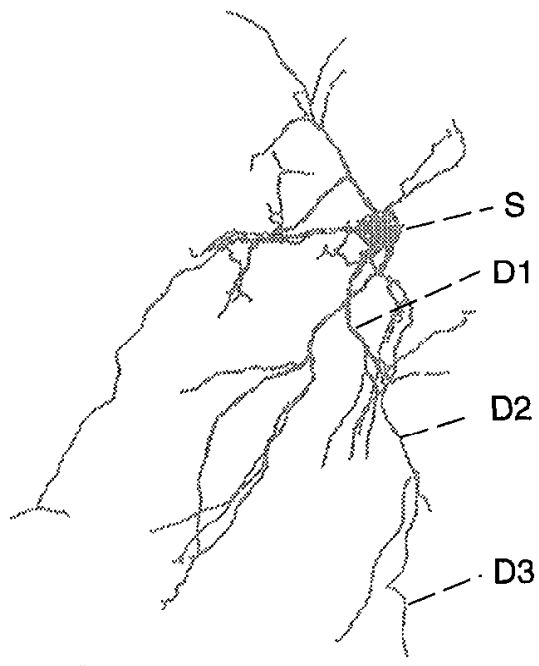

Voltage-clamp
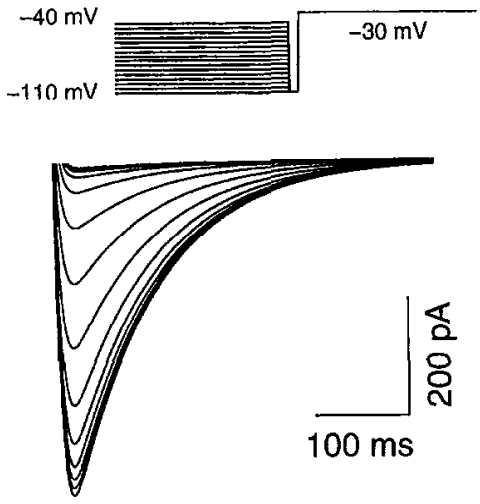

\section{Current-clamp}

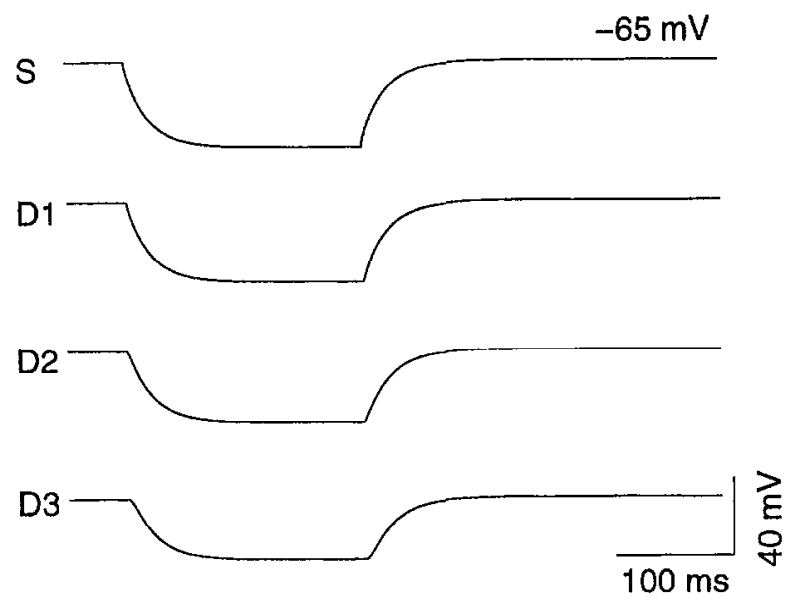

\section{High distal density of T-current}
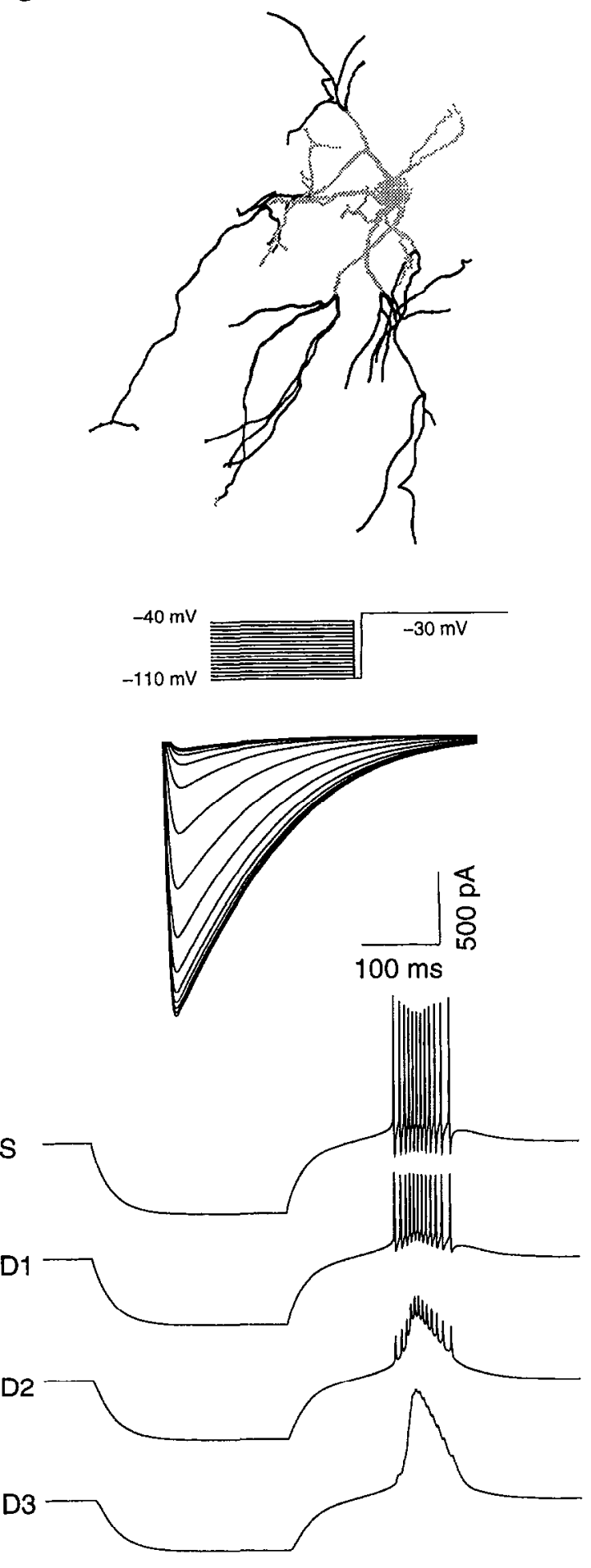

Figure 7. Simulations of voltage-clamp and current-clamp protocols in intact RE cells. The detailed morphology of the RE cell was used with different densities of $I_{T S} . S, D I, D 2$, and $D 3$ indicate dendritic locations of recording sites depicted below. Left, With a uniform density of $0.045 \mathrm{mS} / \mathrm{cm}^{2}$, no low-threshold burst can be elicited from current injection in the soma $(0.3 \mathrm{nA}$ during $200 \mathrm{msec})$. Right, With a higher density of $0.6 \mathrm{mS} / \mathrm{cm}^{2}$ in distal dendrites (shown in black), bursting behavior can be generated in current-clamp. The slow rise of the burst and the accelerando-decelerando pattern of spikes were most prominent with dendritic $I_{T s}$. In hoth cases shown here, the voltage-clamp behavior was consistent with the current amplitudes in Figure 6 if the dendrites were removed.

would be much slower at the lower temperature used in dissociated cell experiments. In the model, this property arose only in intact cells with a high density of dendritic $I_{T s}$. As a consequence of the poor voltage-clamp of the dendrites, dendritic current transients occurred and added a slower component to the current decay seen in the soma (Fig. 10). However, the space clamp was 


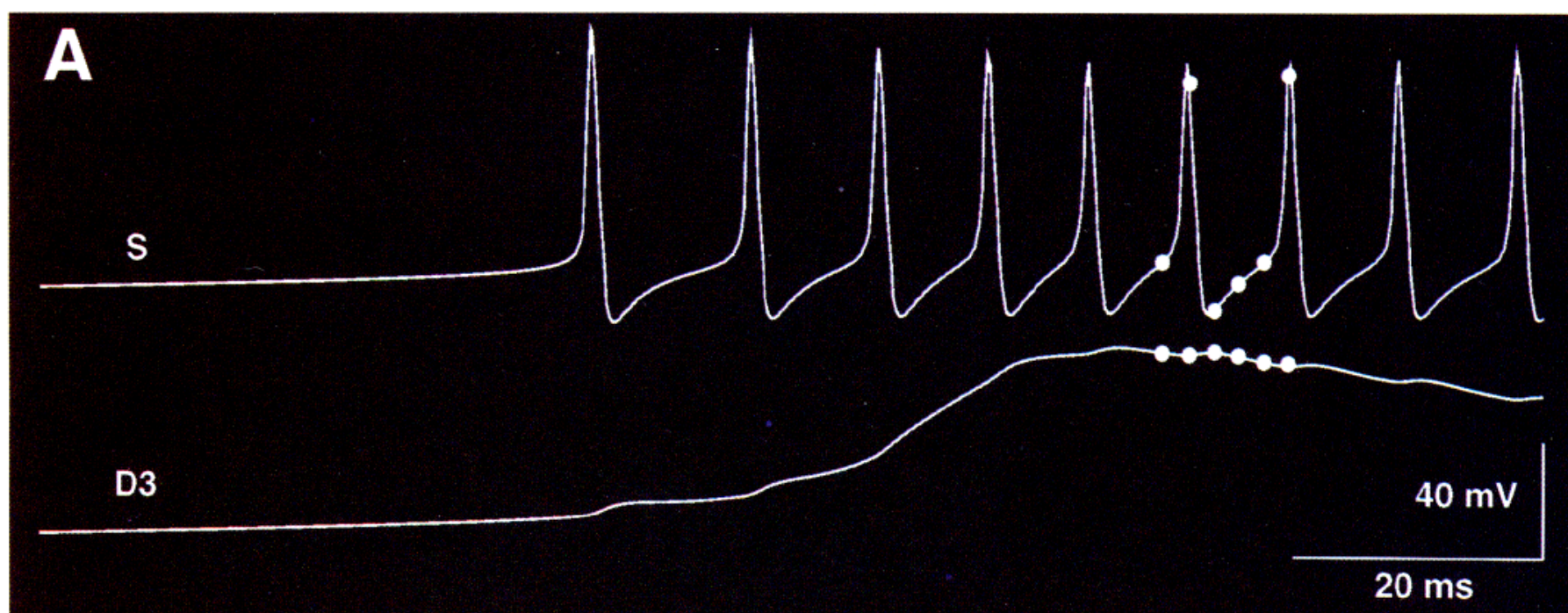

\section{$\mathbf{B}$}

\section{Spatial distribution of membrane potential}

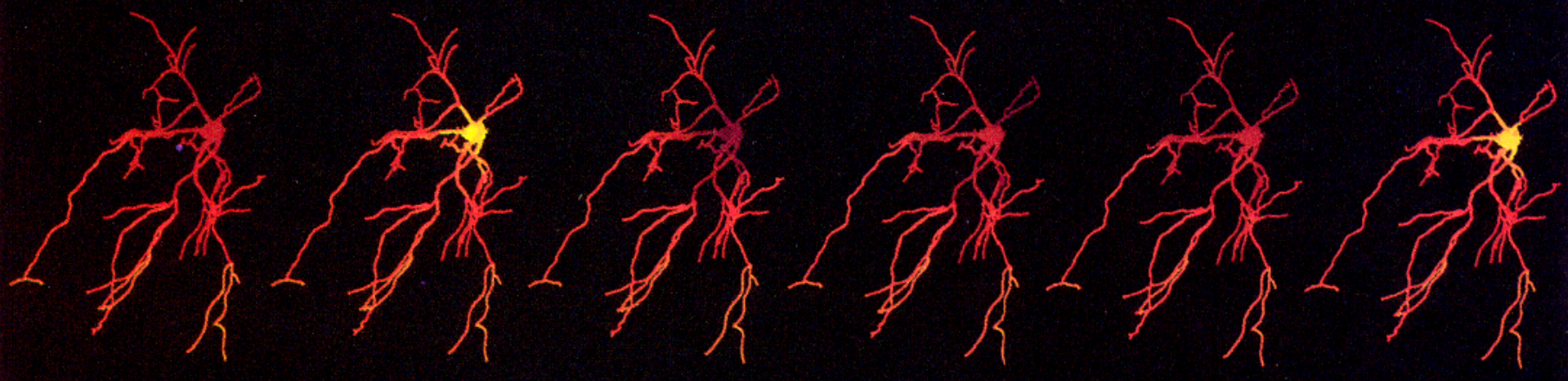

$\begin{array}{llllll}-60 & -40 & -20 & 0 & 20 & (\mathrm{mV})\end{array}$

\section{Dendritic membrane potential profile}
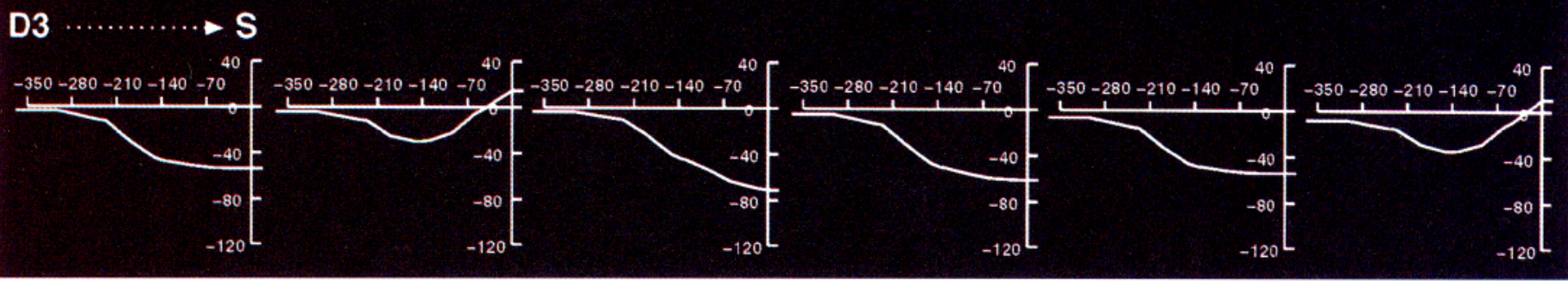

Figure 8. Distribution of the membrane potential during dendritically generated bursts. $A$, Expansion of the somatic and dendritic membrane potential during a burst (same simulation as in Fig. 7, bottom right). B. Snapshots of electrical activity in the cell. The distribution of membrane potential is indicated by colors, as shown in the color scale. The six successive frames correspond to the six circles indicated in $A$. $C$, Profile of the membrane potential along a path from distal dendrite to the soma (from D3 to S in Fig. 7). The abscissa shows the distance from soma (in $\mu \mathrm{m}$ ), and the ordinate shows the membrane potential along this path (in $\mathrm{mV}$ ).

almost perfect in the dissociated cell model (data not shown), suggesting that in this preparation the estimates of the kinetics of the T-current were reliable (see Huguenard and Prince, 1992).
Fourth, presumed dendritic impalements of RE cells in vivo show a burst structure dominated by a broad spike with smaller-amplitude spikes (Fig. 11). The broad spike presum- 
Intact cell

\section{A}
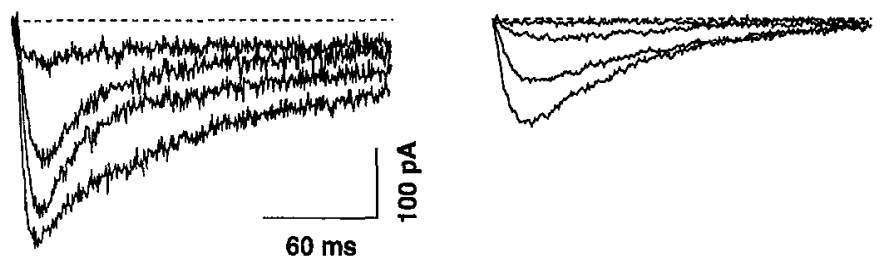

B
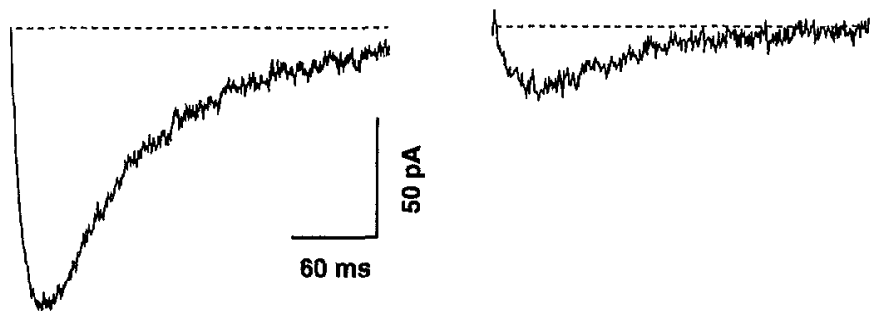

Figure 9. Comparison of voltage-clamp recordings of $I_{T s}$ in intact and acutely dissociated RE cells in vitro. $A$, Activation protocols for $I_{T s}$ in an intact cell (left) compared with an acutely dissociated cell (right). The command potentials were $-60,-50,-40$, and $-30 \mathrm{mV}$ (left) and -50 , $-40,-30$, and $-20 \mathrm{mV}$ (right); both were at $23^{\circ} \mathrm{C}$ (details of the protocols are given in Huguenard and Prince, 1992). The cell at the left had an exceptionally low amplitude of $I_{T S}$; however, it was still higher than that of dissociated cells (see also Fig. $6 A$ ); the time course of inactivation was slower in the intact cell. $B$, Voltage-clamp steps in an intact and a dissociated cell. In the intact cell (left), the holding potential was $-71 \mathrm{mV}$ and the command potential was $-46 \mathrm{mV}\left(34^{\circ} \mathrm{C}\right)$; in the dissociated cell, they were -110 and $-40 \mathrm{mV}$, respectively $\left(23^{\circ} \mathrm{C}\right)$. The amplitude was higher and the time course was slower in the intact cell. $B$ was modified from Figure 1 of Huguenard and Prince (1994).

ably was a calcium spike, whereas the small-amplitude spikes were presumed to be sodium spikes, because they showed the typical accelerando-decelerando structure of RE cells. Sodium spikes with increasing frequency were correlated with the rising phase of the calcium spike, whereas spikes with decreasing frequencies were associated with the decaying phase of the calcium spike. A strikingly similar behavior was observed in the dendritic membrane potential of the model (Fig. 7, right, D2). These obscrvations, together with the stability of the recording and with the negative value of the resting potential, suggest that the impalement was dendritic. These patterns of bursting in the dendrites were generated only when the distal dendritic density of $I_{T s}$ was high.

Finally, another consequence of the possible dendritic localization of $I_{T s}$ is that other currents depending on the entry of $\mathrm{Ca}^{2+}$ through T-channels might also be localized in the dendrites. For example, a calcium-dependent potassium current, $I_{\mathrm{K}[\mathrm{Ca}]}$, was shown to underlie repetitive bursting in RE cells (Avanzini et al., 1989; Bal and McCormick, 1993).

Our model did not generate rhythmic bursting from steady inputs because this current was not included. The characteristics of $I_{\mathrm{K}[\mathrm{Ca}]}$ present a complex problem. This current activates relatively slowly, as indicated by the broadness of the burst in RE cells, but it also must deactivate relatively quickly to allow repetitive bursting to occur at frequencies of $-10 \mathrm{~Hz}$ (Avanzini ct al., 1989; Bal and McCormick, 1993). More data are needed before we can design precise models to investigate a somatic versus dendritic localization for $I_{\mathrm{K}[\mathrm{Ca}]}$.

\section{Properties of RE bursts in vivo}

Perhaps the major consequence of the dendritic T-current is that dendritic synaptic currents potentially can exert a powerful control of the bursting properties of RE cells. With dendritic Tcurrent, we have shown above that the model reproduced the burst properties seen in slices, but it did not account for the graded properties of the bursts seen in vivo (see Fig. 4). In this section, we test the possibility that the presence of additional depolarizing currents in the dendrites could lead to graded bursting behavior.

A series of previous computational studies have considered the effects of synaptic bombardment on the passive and integrative properties in other types of neurons (Holmes and Woody, 1989; Bernander et al., 1991; Rapp et al., 1992). These studies found significant decreases in the input resistance and the time constant, as well as a reduced effectiveness of a single postsynaptic potential to discharge the cell, but did not investigate the effect on intrinsic properties. A modeling study of Purkinje cells simulated the effect of dendritic synaptic currents on the firing patterns of the cell, which were close to in vivo recordings in the presence of synaptic bombardment (De Schutter and Bower, 1994). We estimate here the impact of synaptic currents on the properties of the bursts in RE cells by adding sustained depolarizing currents distributed uniformly on the dendritic tree.

An intact RE cell with distal dendritic $I_{T s}$ was used to study the effect of additional dendritic currents on burst generation. In current-clamp mode, the RE cell model normally generated all-or-none burst responses (Fig. $12 A$ ), in agreement with recordings of RE cells in vitro (see Fig. 5) (see also Llinás and Geijo-Barrientos, 1988). For depolarizing pulses of progressively larger amplitudes, the bursts in the model appeared fully developed, and the pattern of spikes remained similar for stronger current pulses. It was possible to ohtain intermediate patterns, but only by carefully tuning the current amplitude, because these patterns only occurred in a very narrow range (data not shown).

In contrast, a graded burst response was observed in RE cells in vivo (Fig. 4) (see also Fig. 5 in Contreras et al., 1993). A possible reason for this discrepancy is that, in vivo, RE cells are continuously bombarded by excitatory synaptic inputs from thalamic and cortical origin; the depolarizing dendritic current caused by this input might counteract the activation of the T-current in the dendrites. Using the same model as in Figure $12 A$, with an additional depolarizing conductance uniformly distributed in the dendrites, the RE cell generated bursts in a graded manner (Fig. $12 B$ ). These graded burst responses were in agreement with in vivo recordings.

It was difficult to determine the exact amount of depolarizing current equivalent to synaptic bombardment, and a wide range of possible densities and reversal potentials was used. The tendency for generating graded bursting behavior depended on the intensity of the depolarizing current; a typical model with a moderate intensity is shown in Figure 12B. For higher intensities, it became increasingly difficult to generate a burst, which suggests that tonic bombardment of the dendritic tree could have a decisive control on burst generation, through depolarization and inactivation of $I_{T S}$.

We also tested the possibility of generating graded bursting behavior from a purely somatic current $(0 \mathrm{mV}$ reversal) representing, for example, the leak caused by electrode impalement. In this case, we could not obtain a graded burst response. In the 


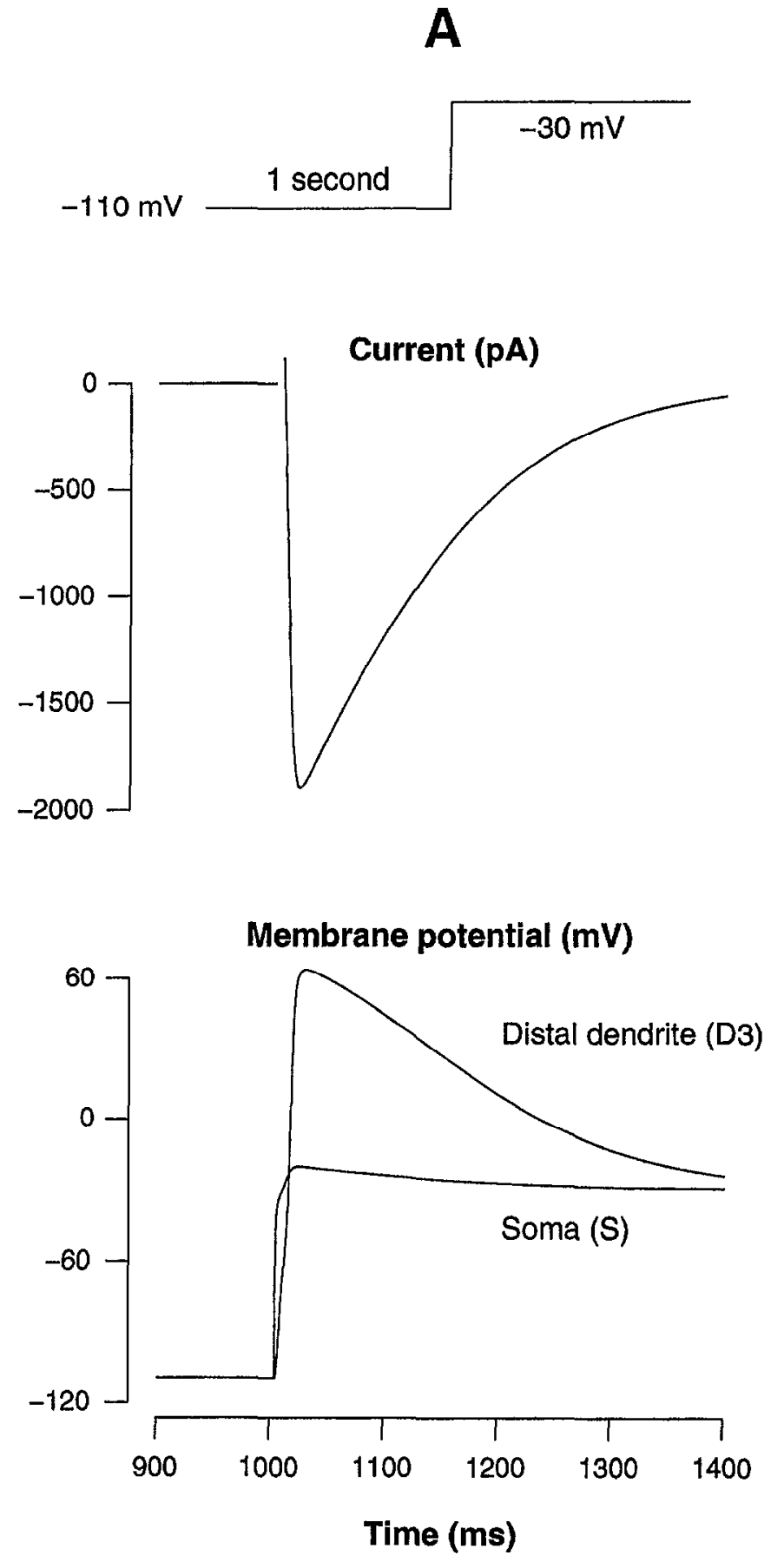

\section{Dendritic membrane potential profile}
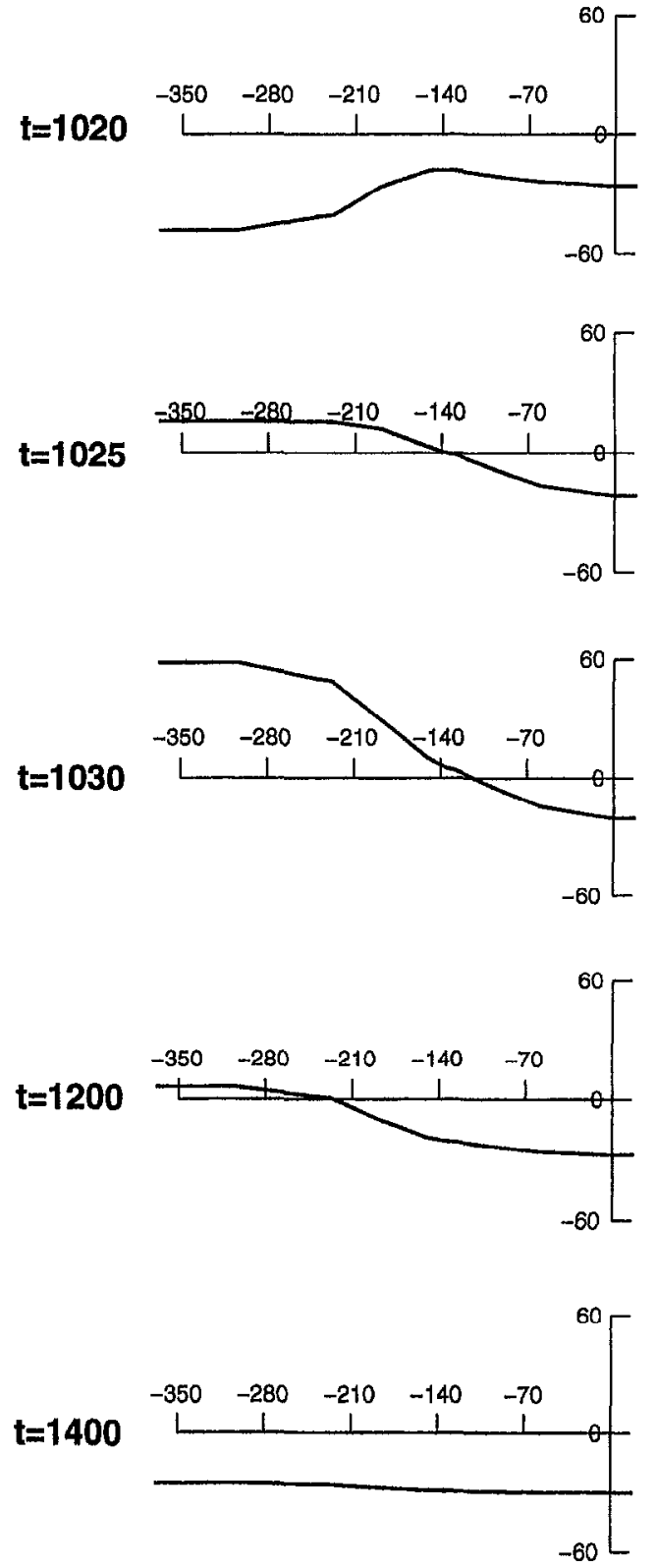

Figure 10. Poor access to the dendrites of RE cells in voltage-clamp mode. $A$, Voltage-clamp protocol similar to Figure 7 with a high density of distal T-current. In addition to the current recorded at the electrode, the somatic and distal dendritic membrane potentials are shown (S and D3 are as described in Fig. 7). The deviation from voltage-clamp in the dendrites is pronounced. Similar results were obtained using constant field equations for $I_{T S}$. $B$, Dendritic membrane potential profile (defined identically as in Fig. 8) taken during the voltage-clamp protocol in $A$ (same units of time as in $A$ ). From an initially good space clamp at $-110 \mathrm{mV}$, the attempt to clamp the cell at $-30 \mathrm{mV}$ was unsuccessful because of powerful current transients in the dendrites, which could not be controlled from the soma. Because of these transients, the kinetics of the current recorded in the soma appears to be slower than in dissociated cells.

model, bursting is generated in the dendrites and the only way to alter its properties is to change the balance of currents in the dendrites.

\section{Reduced models}

Models that incorporate morphological details of the dendritic tree are certainly relevant to study single-cell behavior. However, simulating large-scale networks requires using simplified models that are more efficient to simulate. Another application of reduced models is hybrid recordings, in which a simulated cell is connected artificially to a recording from a real cell (Yarom, 1991; LeMasson et al., 1992; Renaud-LeMasson et al., 1993). This hybrid method requires models that can be simulated in real time, while still conserving a sufficient degree of realism. In this section, we examine one- and three-compartment 

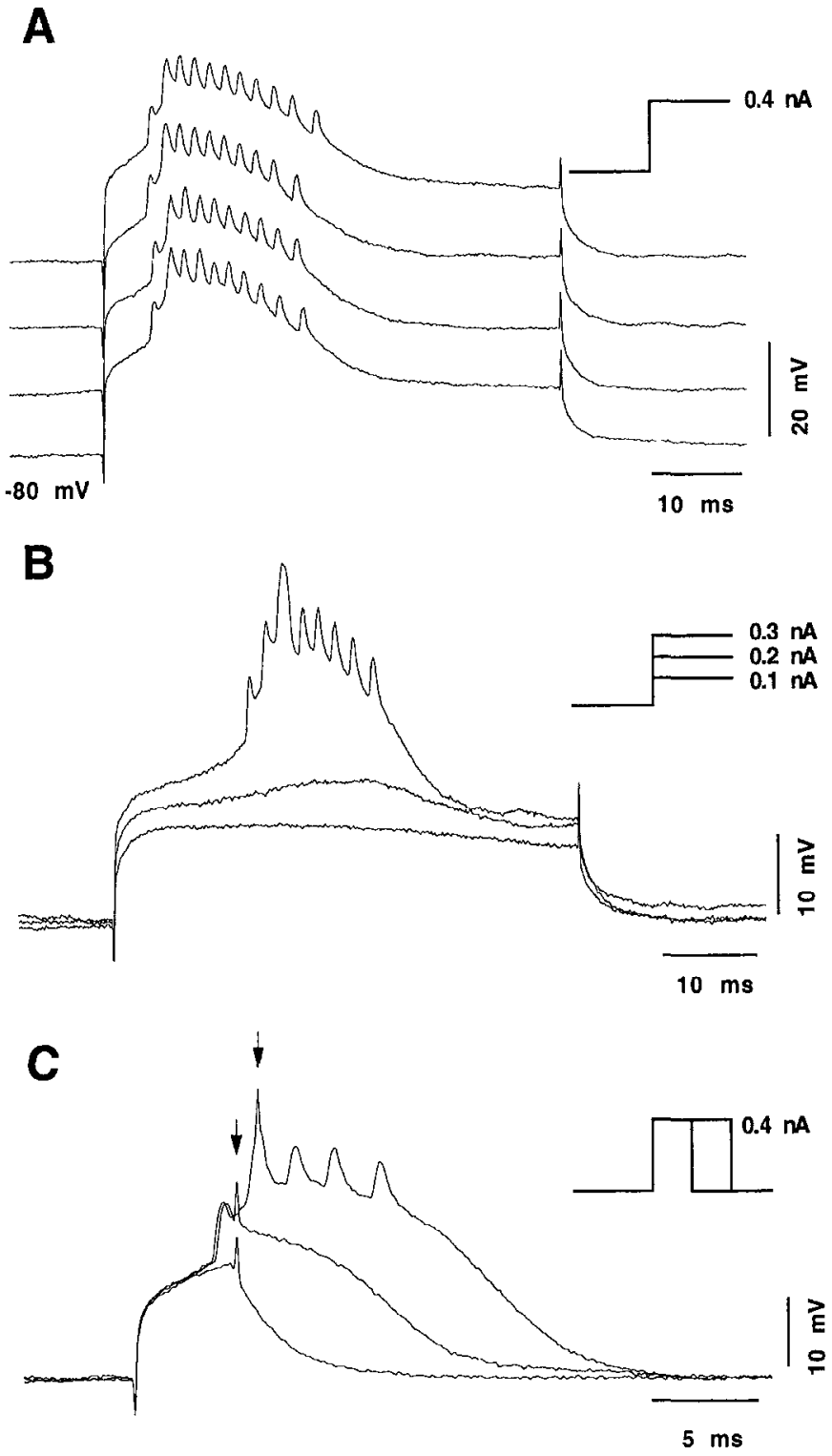

Figure 11. Presumed in vivo dendritic recording of an $\mathrm{RE}$ cell from the rostrolateral sector in a urethane-anesthetized cat. $A$, Depolarizing current pulses of constant intensity applied at a hyperpolarized membrane potential elicited an active response that was crowned by small spike potentials (presumably electrotonically attenuated somatic spikes) with a stereotyped bursting pattern in which the first interval is slightly longer with the frequency increasing then decreasing during the response. Four different responses, displaced vertically for clarity, indicate the stereotyped burst response. $B$, In response to depolarizing pulses of increasing amplitudes, a passive response was obtained first then an active response of small amplitude and, finally, a fully developed burst. Increasing the amount of current injected (as in $A$ ) only decreased the latency to the burst but did not change its stereotyped shape. $C$, Increasing the duration of a constant amplitude depolarizing current pulse also elicited a burst. The shorter pulse occasionally elicited active responses that did not develop into a burst. The arrows indicate the end of the current pulses. All of the pulses in the figure were applied at the same membrane potential (indicated in $A$ ).

models derived from the detailed morphological model of the RE cell.

We applied a procedure for simplifying the dendritic morphology, as described in Materials and Methods, to obtain a model with three compartments. The passive properties were assumed to be the same as described above, and the minimal model was fitted to the voltage-clamp recordings using a simplex algorithm. Using the dendritic correction, $C_{d}$ in Eq. 3 , as the only parameter, we obtained an excellent fit of the voltage-clamp recording (Fig. $2 B$ ).

The kinetics and localization of $I_{T s}$ were investigated in the reduced model. Voltage-clamp traces obtained with a uniform density of $I_{T S}$ of $0.045 \mathrm{mS} / \mathrm{cm}^{2}$ were similar to those in the intact cell model with the same density. As in the more detailed model, the current-clamp behavior did not show bursting activity (Fig. 13, left) and the uniform density of $I_{T s}$ had to be increased by about an order of magnitude to observe bursts (data not shown).

With a higher distal density of $I_{T S}$, the minimal model showed bursting behavior that was remarkably similar to that in the detailed morphological model (compare Figs. 7 and 13). However, the threshold for bursting behavior was slightly different than in the detailed model. The properties of the bursts generated by distal $I_{T S}$ were the same as described above for the intact cell: namely, they had a slow rise and decay, they needed strong current pulses to be evoked, and they possessed the typical accclcrando-decelerando pattern of sodium spikes (Fig. 13, right). Graded burst responses could be simulated using the three-compartment model as well, using similar densities of currents as the detailed model (data not shown).

Finally, we investigated bursting behavior using a single-compartment model of the RE cell. The size of the compartment was determined by fitting the passive properties to voltage-clamp recordings of an $\mathrm{RE}$ cell (Fig. 14A). The single-compartment model could not capture all of the details of the capacitive transients but nevertheless provided an acceptable fit. Using a density of $I_{T s}$ close to threshold for bursting behavior, the singlecompartment model generated bursts in response to injection of current pulses (Fig. 14B). The burst still had a relatively broad structure, although narrower than in the presence of dendrites. However, it was not possible to obtain the typical accelerandodecelerando structure of sodium spikes. Nonetheless, the first spike intcrval of the burst shown in Figure $14 B$ was larger than for the subsequent ones.

More importantly, depolarizing currents were ineffective in obtaining the graded burst response found in models having dendritic $I_{T s}$.

\section{DISCUSSION}

We have explored computational models in concert with intracellular recordings performed in vivo and in vitro, and we conclude that calcium currents in dendrites are essential for generating the bursting responses of RE cells. We discuss here the validity of this conclusion as well as the broader significance of the model for the function of the thalamic reticular nucleus.

\section{Evidence for dendritic calcium currents}

Originally suggested by Mulle et al. (1984), the hypothesis that $I_{T s}$ is localized in the dendrites is now favored by several lines of experimental evidence. The primary contribution of the model is to show that these experimental data, sometimes contradictory, are reconciled if we assume that the major proportion of $I_{T s}$ is located in the distal portions of the dendrites. We review here the rationale for this explanation.

(1) The amplitude of $I_{T s}$ is much larger in intact than in acutely dissociated RE cells, suggesting dendritic localization. In dissociated cells, only the proximal parts of the dendrites are present, and the lower amplitude is attributable to the removal of the 
A

All-or-none bursts (Soma)
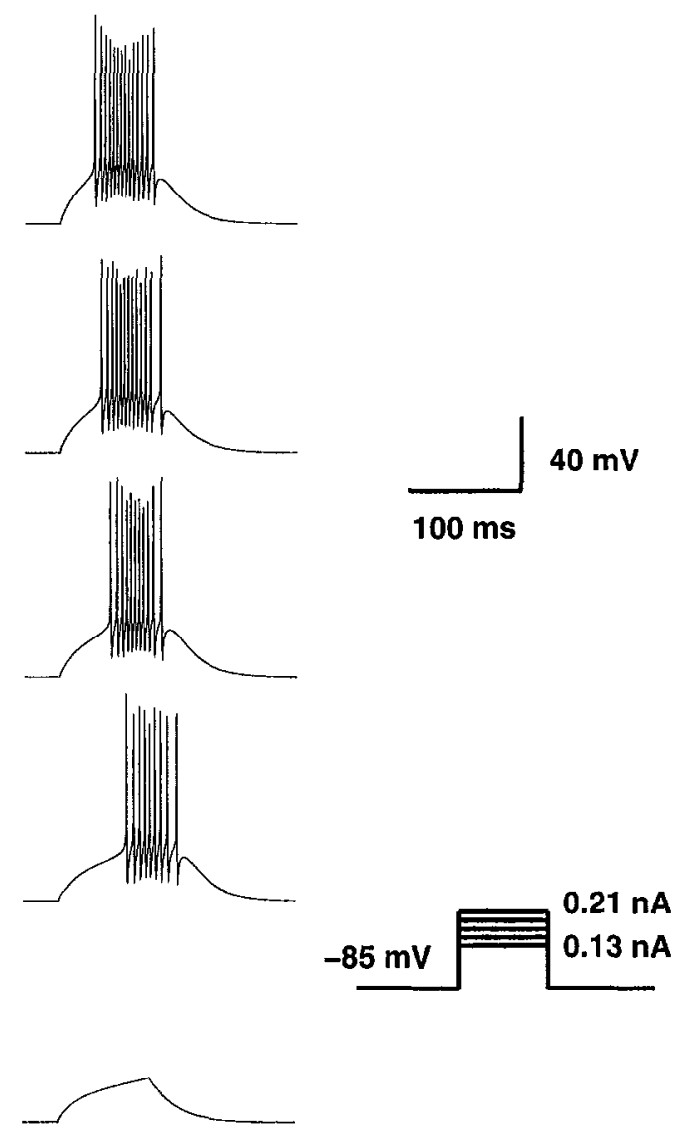

\section{All-or-none bursts (Distal dendrites)}

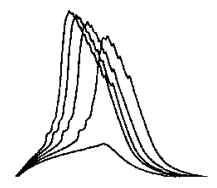

B

\section{Graded bursts \\ (Soma)}

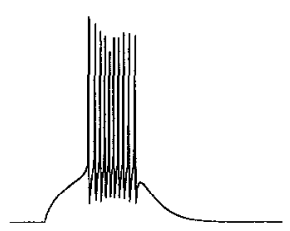

$40 \mathrm{mV}$
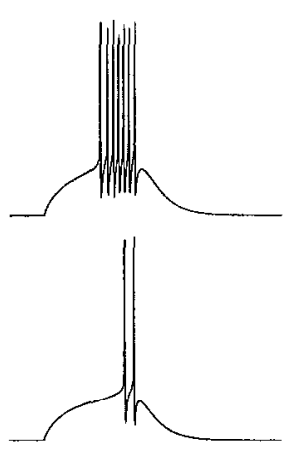

Figure 12. Graded and all-or-none properties of RE bursts. Bursting behavior was elicited by depolarizing current pulses from $-85 \mathrm{mV}$ in the simulated intact RE cell. The time courses of the membrane potential in the soma (top) and in the distal dendrites (superimposed, bottom) are indicated. $A$, All-or-none bursts in the intact RE cell with high clensity of $I_{7 s}$ in distal dendrites and no additional dendritic current (same parameters as in Fig. 7, right). The membrane potential in the distal dendrite (bottom) shows that there is a threshold for bursting behavior. $B$, Graded bursts in the presence of a sustained depolarizing current uniformly distributed in the dendrites (same simulation as in $A$, but with an additional conductance of $0.02 \mathrm{mS} / \mathrm{cm}^{2}$ density and -20 $\mathrm{mV}$ reversal potential). In this case, the number of action potentials in the burst was proportional to the amplitude of the current pulse.

major pool of T-channels by the dissociation procedure. Alternatively, the T-channels somehow might be altered by the dissociation procedure, in which case the difference in amplitude would be artifactual. The higher amplitude of T-current in dissociated TC cells compared with dissociated RE cells (Huguenard and Prince, 1992) argues against this possibility. This difference also implies that there is less T-current in the dendrites of TC cells compared with RE cells.

(2) The threshold for burst generation is higher in RE cells than in TC cells, suggesting that the burst in RE cells is generated away from the soma. Although $I_{T s}$ activation is shifted to positive potentials compared with relay cells, this difference in voltage dependence is not sufficient to explain the larger difference in burst threshold. The appropriate high threshold was obtained in the present model only if $I_{T S}$ were located in distal dendrites and if the cell had a relatively high axial resistance, consistent with results from fitting the detailed morphological model to the recordings of the same cell. During current injection in the model, there was a voltage difference between the soma and distal dendrites of $\sim 9 \mathrm{mV}$ at steady state (Fig. 7) because of electrotonic attenuation. The immediate consequence is that more hyperpolarizing current is needed to reach the level of deinactivation of $I_{7 \mathrm{~s}}$ in the dendrites. Because some RE neurons are larger than the cell studied here (see Jones, 1985), this effect would be even more prominent in adult animals.

(3) The accelerando-decelerando pattern of fast spikes within the burst is consistent with dendritic $I_{T S}$. We could not replicate this characteristic pattern in the absence of dendrites (Fig. 14). On the other hand, accelerando-decelerando patterns were present in the intact cell with purely somatic current but, in this case, the peak amplitude of $I_{T S}$ was $\sim 2.5 \mathrm{nA}$, which is inconsistent with voltage-clamp recordings in dissociated 


\section{Uniform density of T-current}

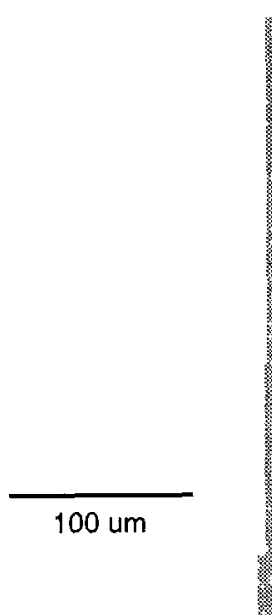

D2

D1

$\mathrm{S}$

\section{Voltage-clamp}
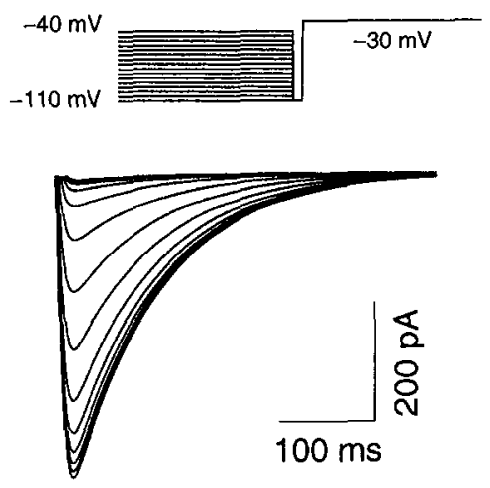

\section{Current-clamp}

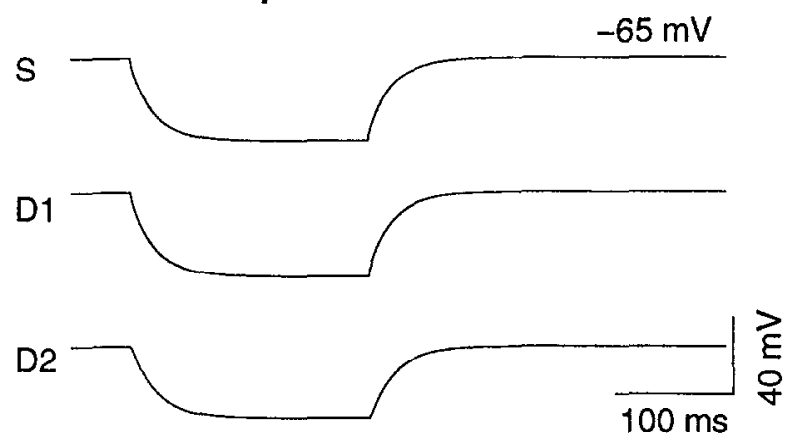

\section{High distal density of T-current}
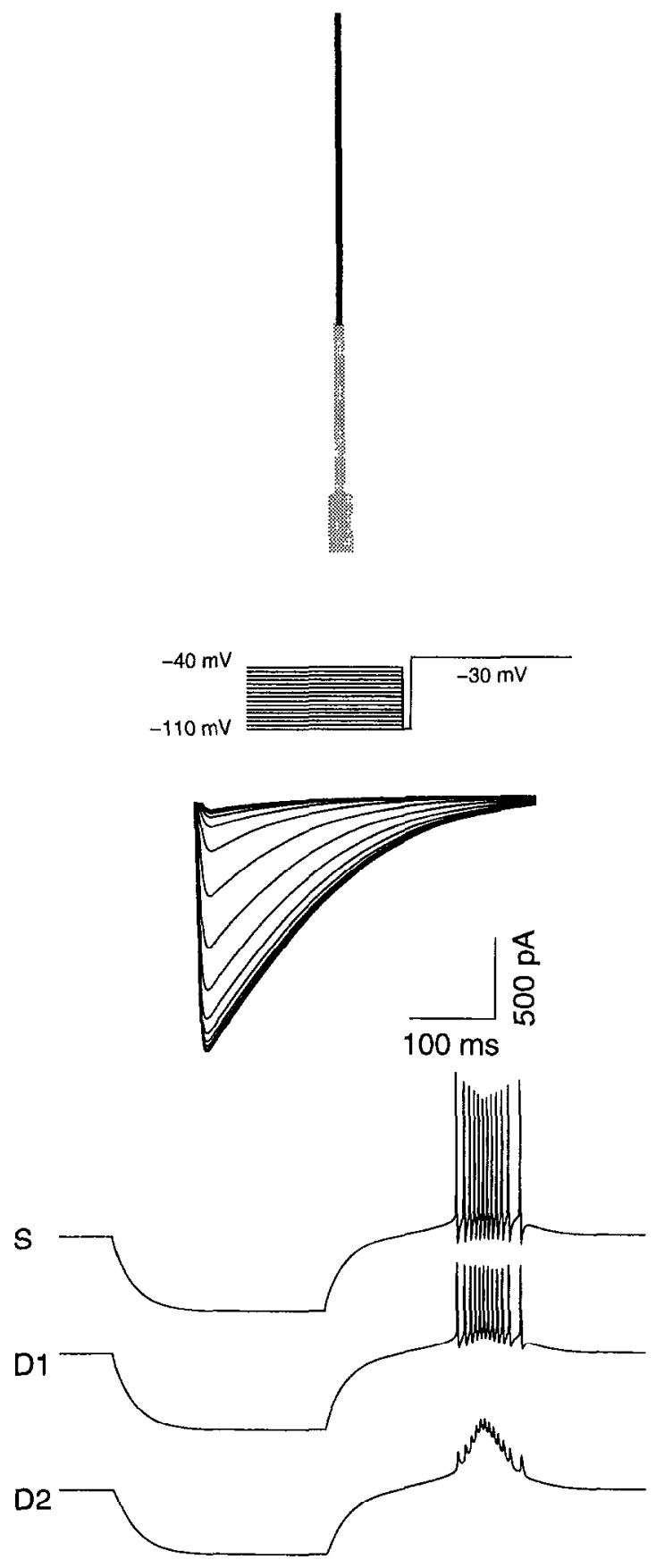

Figure 13. Voltage-clamp and current-clamp protocols in a reduced model of an RE cell. Starting from the morphology of the cell shown in Figure 1A, the simplification procedure led to three compartments: the soma $(S)$, proximal $(D I)$, and distal $(D 2)$ dendritic compartments (corresponding approximately to S, D1, and D2 in Fig. 7). Right, Uniform density of $I_{r 3}$ of $0.045 \mathrm{mS} / \mathrm{cm}^{2}$. In current-clamp, no low-threshold burst could be elicited from current injection in the soma $(0.3 \mathrm{nA}$ during $200 \mathrm{msec})$. Right, Higher density of $I_{\mathrm{Ts}}$ in distal dendrites $\left(0.68 \mathrm{mS} / \mathrm{cm}^{2}\right)$. In this case, similar bursts with a slow rise and an accelerando-decelerando pattern of spikes are seen, as in Figure 7 . The simulation of this model was $\sim 25$ times faster than the detailed morphological model. In both cases shown here, the voltage-clamp behavior was consistent with Figure 6 in the absence of distal dendrites.

cells. The accelerando-decelerando patterns were more robust in models that included distal $I_{T s}$; we propose that this property arises in the RE cell from the slowly increasing current load provided by a $\mathrm{Ca}^{2+}$ spike occurring in distal dendrites. The long duration and the slow rise of the burst in RE cells can be explained by the same mechanism, in addition to the slower kinetics of $I_{T s}$ (Huguenard and Prince, 1992).
(4) The voltage trace in the dendrites of the model during the burst was consistent with the presumed dendritic recordings in RE cells (Fig. 11). These recordings show a broad spike with lowamplitude sodium spikes, which is atypical for RE cells. It is possible that the cell was damaged, but the stability of the recording and of the response, as well as the low resting membrane potential, suggest that this was not the case. The striking resem- 


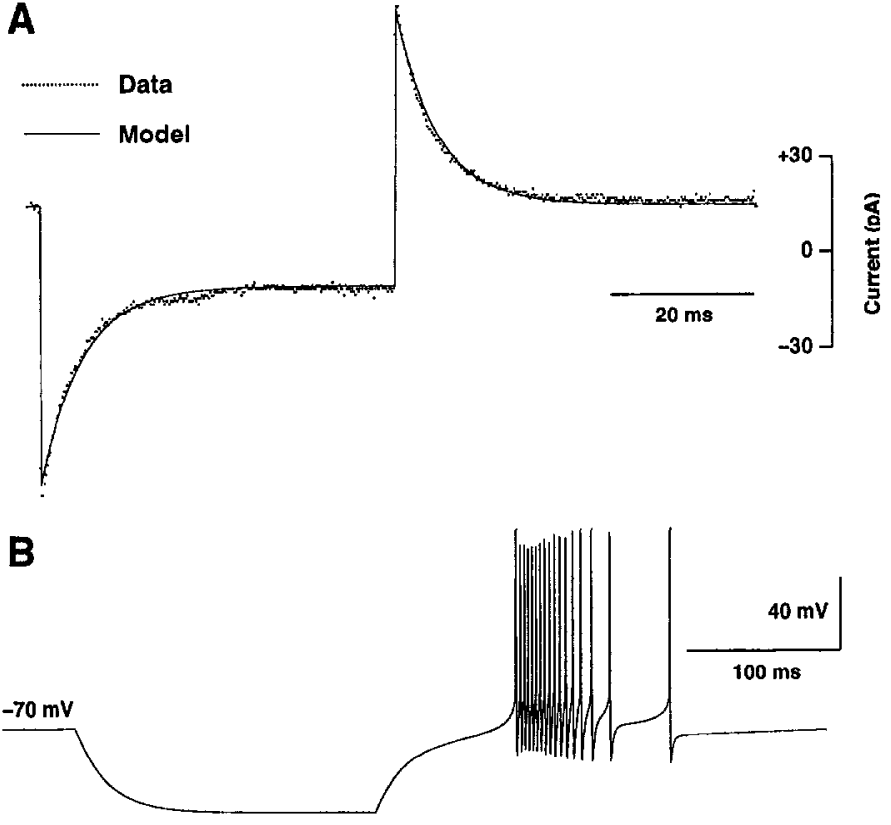

Figure 14. Single-compartment model of the RE cell. $A$, Simplex fitting of a single-compartment model to estimate the optimal size for the cell. The fit gave an equivalent cylinder of $l=64.52 \pm 0.01 \mu \mathrm{m}$ with a diameter of $70 \mu \mathrm{m}$. Other parameters were identical to Figure $2 A$; the least-square error, however, was larger in this case $(\sim 3 \%) . B$, Low-threshold burst obtained in this model after current injection $(0.3 \mathrm{nA}$ during $200 \mathrm{msec}$; density of $I_{T s}=3 \mathrm{mS} / \mathrm{cm}^{2}$ ). In this case, there is no accelerandodecelerando pattern of spikes, and the cell could not produce graded bursting behavior.

blance with the dendritic potential in the model is consistent with a dendritic impalement.

(5) The kinetics of $I_{T S}$ was slower in intact RE cells than in acutely dissociated cells. This was reproduced in the model when the $T$-current was located in distal dendrites. The model revealed the difficulty of voltage-clamping dendrites with active currents. Additional current transients of dendritic origin were evoked during voltage-clamp in the soma and could be interpreted incorrectly as a slower kinetics of the current.

(6) In the model, the RE cell could generate graded bursting behavior only if it had dendritic $I_{T S}$. As discussed in more delail below, this is typical of RE cells in vivo (Contreras et al., 1993) and is entirely consistent with a competition between extrinsic and intrinsic currents occurring in the dendrites. It might be that other currents also contribute to this response.

(7) Although RE neurons have been classified in different morphological classes (Spreafico et al., 1991), no clear differences in electrophysiological properties have been correlated with this morphological diversity (but see Contreras et al., 1992). We found remarkably similar bursting properties from different models provided that there was a high density of $I_{T S}$ in the dendrites. All of the above properties could be reproduced with a model with as few as three compartments. Taken together, these data suggest that morphology has little influence on electrophysiological properties recorded in the soma. The morphological characteristics of RE neurons might be related, rather, to the organization of synaptic inputs.

A similar approach may be taken with other types of neurons in which dendritic conductances might determine their electrophysiological behavior. Abundant evidence exists for the involvement of dendritic currents in the bursting properties of other types of cells (e.g., Traub and Miles, 1991). The comparison of intracellular recordings with and without dendrites, tracing of the stained cells, and simulating the dendritic morphology are promising procedures for investigating these problems.

\section{Impact of dendritic calcium currents on the electrophysiological properties}

The dendritic localization of $I_{T s}$ potentially can have several important consequences for the behavior of RE cells.

First, GABAergic collaterals between RE neurons have been identified (Jones, 1985; Bal et al., 1995; Liu et al., 1995). Intracellular recordings reveal GABAergic IPSPs in RE cells (Destexhe et al., 1994a; Bal et al., 1995), but they are of relatively low amplitude. However, if the T-current is dendritic, IPSPS arising from neighboring $\mathrm{RE}$ cells might initiate rebound bursts in localized dendritic regions, without necessarily any evidence of IPSP in somatic recordings. Moreover, as suggested by a recent model (Destexhe et al., 1994b), the depolarization of RE cells provided by neuromodulatory inputs promotes their sensitivity to IPSPs because $I_{T S}$ tends to be more deinactivated. The possibility of rebound bursts in GABAergically connected RE cells could be tested by stimulating RE cells after blockade of excitatory synaptic transmission and looking for rebound bursts.

Second, in a network of interconnected RE cells, dendritic $I_{T s}$ opens new possibilities for generating oscillatory behavior. In cats, the RE nucleus is characterized by the presence of dendrodendritic GABAergic synapses (Deschênes et al., 1985; Yen et al., 1985). GABAergically connected cells with a rebound burst response readily oscillate (Perkel and Mulloney, 1974; Destexhe and Babloyantz, 1992; Wang and Rinzel, 1992; Destexhe et al., 1994a,b; Golomb et al., 1994). As proposed previously (Deschênes et al., 1985; Mulle et al., 1986), it is possible that, through dendro-dendritic synapses, GABAergically connected RE cells could generate synchronized oscillations, as in the case of the dcafferented RE nucleus in vivo (Steriade et al,, 1987). The possibility of having many local oscillators in GABAergically connected dendrites of RE cells opens a range of possibilities for more complex oscillatory behavior (Destexhe et al., 1994a).

Third, if dendritic branches containing a high density of $I_{T s}$ are hyperpolarized, the deinactivated $\mathrm{T}$-current could provide high sensitivity to incoming EPSPs and could efficiently generate burst discharges. This possibility was suggested earlier (Contreras et al., 1993) and is now supported by recent experiments showing that strong corticothalamic excitatory volleys can trigger dendritically generated bursts in RE cells and promote spindle oscillations (Contreras and Steriade, 1995; Contreras and Steriade, in press).

Taken together, the above observations suggest that a range of complex interactions can take place in the dendrites of RE cells. Mutual inhibition between RE cells can have different effects on triggering, shunting, or shortening burst discharges, in a manner that depends critically on the membranc potential (see also Destexhe et al., 1994b).

Finally, the dendritic origin of burst discharges suggests a new mechanism by which RE cells could participate in the control of the transition of the thalamocortical system between wakefulness and sleep. In the present model, the presence of additional depolarizing currents in the dendrites counteracted the genesis of the burst. This behavior could not be observed in a single-compartment model, suggesting that the soma with sodium spikes and the dendrites with calcium spikes constitute a device that functions according to the synaptic input received. The den- 
drites of RE cells would then "sample" the amount of synaptic activity between the thalamus and the cortex and tune the responsiveness of the RE nucleus according to these inputs. For sustained input, which occurs during tonic activity in the thalamus and cortex, the RE cell does not have the tendency to fire bursts. For more phasic inputs, as during synchronized sleep, the dendrites no longer would be bombarded in a sustained manner, and bursting behavior would be promoted.

We propose that this type of interplay of currents in the dendrites acts in concert with neuromodulation in switching the thalamus between tonic and bursting modes.

\section{REFERENCES}

Avanzini G, de Curtis M, Panzica F, Spreafico R (1989) Intrinsic properties of nucleus reticularis thalami neurones of the rat studied in vitro. J Physiol (Lond) 416:111-22.

Bal T, McCormick DA (1993) Mechanisms of oscillatory activity in guinea-pig nucleus reticularis thalami in vitro: a mammalian pacemaker. J Physiol (Lond) 468:669-691.

Bal T, von Krosigk M, McCormick DA (1995) Role of the ferret perigeniculate nucleus in the generation of synchronized oscillations in vitro. J Physiol (Lond) 483:665-685.

Barrett JN, Crill WE (1974) Influence of dendritic location and membrane properties on the effectiveness of synapses on cat motoneurones. J Physiol (Lond) 239:325-345.

Bernander O, Douglas RJ, Martin KA, Koch C (1991) Synaptic background activity influences spatiotemporal integration in single pyramidal cells. Proc Natl Acad Sci USA 88:11569-11573.

Bush PC, Sejnowski TJ (1993) Reduced compartmental models of neocortical pyramidal cells. J Neurosci Methods 46:159-166.

Cauller LJ, Connors BW (1992) Functions of very distal dendrites: experimental and computational studies of Layer I synapses on neocortical pyramidal cells. In: Single neuron computation (McKenna T, Davis J, Zornetzer SF, eds). Boston: Academic.

Contreras D, Curro Dossi R, Steriade M (1992) Bursting and tonic discharges in two classes of reticular thalamic neurons. J Neurophysiol 68:973-977.

Contreras D, Curro Dossi R, Steriade M (1993) Electrophysiological properties of cat reticular thalamic neurones in vivo. J Physiol (Lond) 470:273-294.

Contreras D, Steriade M (1995) Cellular basis of EEG slow rhythms: a study of dynamic corticothalamic relationships. J Neurosci 15:604-622.

Contreras D, Steriade M (1996) Spindle oscillation in cats: the role of corticothalamic feedback in a thalamically-generated rhythm. J Physiol (Lond), in press.

Deschênes M, Madariaga-Domich A, Steriade M (1985) Dendrodendritic synapses in the cat reticularis thalami nucleus: a structural basis for thalamic spindle synchronization. Brain Res 334:165-168.

De Schutter E, Bower JM (1994) An active membrane model of the cerebellar Purkinje cell. II. Simulation of synaptic responses. J Neurophysiol 71:401-419.

Destexhe A, Babloyantz A (1992) Cortical coherent activity induced by thalamic oscillations. In: Neural network dynamics (Taylor JG, Caianello ER, Cotterill RMJ, Clark JW, eds), pp 234-249. Berlin: Springer.

Destexhe A, Contreras D, Sejnowski TJ, Steriade M (1994a) A model of spindlc rhythmicity in the isolated thalamic reticular nucleus. J Neurophysiol 72:803-818.

Destexhe A, Contreras D, Sejnowski TJ, Steriade M (1994b) Modeling the control of reticular thalamic oscillations by neuromodulators. NeuroReport 5:2217-2220.

Destexhe A, McCormick DA, Sejnowski TJ (1993) A model for 8-10 Hz spindling in interconnected thalamic relay and reticularis neurons. Biophys J 65:2474-2478.

Domich L, Oakson G, Steriade M (1986) Thalamic burst patterns in the naturally sleeping cat: a comparison between cortically projecting and reticularis neurones. J Physiol (Lond) 379:429-449.

Golomb D, Wang XJ, Rinzel J (1994) Synchronization properties of spindle oscillations in a thalamic reticular nucleus model. J Neurophysiol 72:1109-1126.

Hille B (1992) Ionic channels of excitable membrancs. Sunderland, MA: Sinauer.
Hines M (1989) A program for simulation of nerve equations with branching geometries. Int J Biomed Comput 24:55-68.

Hodgkin AL, Huxley AF (1952) A quantitative description of membrane current and its application to conduction and excitation in nerve. $\mathrm{J}$ Physiol (Lond) 117:500-544.

Holmes WR, Woody CD (1989) Effects of uniform and non-uniform synaptic "activation-distributions" on the cable properties of modeled cortical pyramidal neurons. Brain Res 505:12-22.

Huguenard JR, Hamill OP, Prince DA (1989) Sodium channels in dendrites of rat cortical pyramidal neurons. Proc Natl Acad Sci USA 86:2473-2477.

Huguenard JR, Prince DA (1992) A novel T-type current underlies prolonged $\mathrm{Ca}^{2+}$-dependent bursts firing in GABAergic neurons of rat thalamic reticular nucleus. J Neurosci 12:3804-3817.

Huguenard JR, Prince DA (1994) Intrathalamic rhythmicity studied in vitro: nominal T-current modulation causes robust anti-oscillatory ef fects. J Neurosci 14:5485-5502.

Jahnsen H, Llinás RR (1984) Electrophysiological properties of guineapig thalamic neurons: an in vitro study. J Physiol (Lond) 349:205-226.

Jones EG (1985) The thalamus. New York: Plenum.

LeMasson G, Renaud-LeMasson S, Sharp A, Abbott LF, Marder E (1992) Real time interaction between a model neuron and the crustacean somatogastric nervous system. Soc Neurosci Abstr 18:1055.

Liu XB, Warren RA, Jones EG (1995) Synaptic distribution of afferents from reticular nucleus in ventroposterior nucleus of the cat thalamus. J Comp Neurol 352:187-202.

Llinás RR, Geijo-Barrientos E (1988) In vitro studies of mammalian thalamic and reticularis thalami neurons. In: Cellular thalamic mechanisms (Bentivoglio M, Spreafico R, eds), pp 23-33. Amsterdam: Elsevier.

Mainen ZF, Joerges J, Huguenard JR, Sejnowski TJ (1995) A model of spike initiation in neocortical pyramidal neurons. Neuron, in press

Major G, Larkman AU, Jonas P, Sakmann B, Jack JJB (1994) Detailed passive cable models of whole-cell recorded CA3 pyramidal neurons in rat hippocampal slices. J Neurosci 14:4613-4638.

McCormick DA, Huguenard JR (1992) A model of the electrophysiological properties of thalamocortical relay neurons. J Neurophysiol 68:1384-1400.

Mulle C, Madariaga A, Deschênes M (1986) Morphology and electrophysiological properties of reticularis thalami neurons in cat: in vivo study of a thalamic pacemaker. J Neurosci 6:2134-2145.

Perkel DH, Mulloney B (1974) Motor pattern production in reciprocally inhibitory neurons exhibiting postinhibitory rebound. Science 185:181-183

Press WH, Flannery BP, Teukolsky SA, Vetterling WT (1986) Numerical recipes. The art of scientific computing. Cambridge: Cambridge UP.

Rall W (1995) The theoretical foundation of dendritic function (Segev I Rinzel J, Shepherd GM, eds). Cambridge: MIT.

Rall W, Burke RE, Holmes WR, Jack JJ, Redman SJ, Segev I (1992) Matching dendritic neuron models to experimental data. Physiol Rev 72:S159-S186.

Ramon y Cajal S (1909) Histologie du systeme nerveux de l'homme et des vertebres (translated by Azoulay L). Paris: Maloine.

Rapp M, Segev I, Yarom Y (1994) Physiology, morphology and detailed passive models of guinea-pig cerebellar Purkinje cells. J Physiol (Lond) 474:101-118

Rapp M, Yarom Y, Segev I (1992) The impact of parallel fiber background activity on the cable properties of cerebellar Purkinje cells. Neural Comput 4:518-533.

Renaud-LeMasson S, LeMasson G, Marder E, Abbott LF (1993) Hybrid circuits of interacting computer model and biological neurons. In Advanced in neural information processing systems, Vol 5 (Hanson SJ, Cuwan JD, Giles GL, eds), pp 813-819, San Mateo, CA: Morgan Kaufmann.

Rhodes PA, Gray CM (1994) Simulations of intrinsically bursting neocortical pyramidal neurons. Neural Comput 6:1086-1110.

Sejnowski TJ, Destexhe A, Contreras D, Steriade M, Huguenard JR (1995) In vivo, in vitro and computational analysis of dendritic currents in thalamic reticular neurons. Soc Neurosci Abstr 21:1187.

Spreafico R, Battaglia G, Frassoni C (1991) The reticular thalamic nucleus (RTN) of the rat: cytoarchitectural, Golgi, immunocytochemical, and horseradish peroxidase study. J Comp Neurol 304:478-490.

Steriade M, Domich L, Oakson G (1986) Reticularis thalami neurons rcvisited: activity changes during shifts in states of vigilance. J Neurosci $6: 68-81$. 
Steriade M, Domich L, Oakson G, Deschênes M (1987) The deafferented reticular thalamic nucleus generates spindle rhythmicity. J Neurophysiol 57:260-273.

Steriade M, McCormick DA, Sejnowski TJ (1993) Thalamocortical oscillations in the sleeping and aroused brain. Science 262:679-685.

Stratford K, Mason A, Larkman AU, Major G, Jack J (1989) The modeling of pyramidal neurones in the visual cortex. In: The computing neuron (Durbin A, Miall C, Mitchison G, eds), pp 296-321. Workingham, UK: Addison-Wesley.

Stuart GJ, Sakmann B (1994) Active propagation of somatic action potentials into neocortical pyramidal cell dendrites. Nature 367:69-72.

Traub RD (1979) Neocortical pyramidal cells: a model with dendritic calcium conductance reproduces repetitive firing and epileptic behavior. Brain Res 173:243-257.

Traub RD, Miles R (1991) Neuronal networks of the hippocampus. Cambridge: Cambridge UP.

Traub RD, Wong RK, Miles R, Michelson H (1991) A model of a CA3 hippocampal pyramidal neuron incorporating voltage-clamp data on intrinsic conductances. J Neurophysiol 66:635-650. von Krosigk M, Bal T, McCormick DA (1993) Cellular mechanisms of a synchronized oscillation in the thalamus. Science 261:361-364.

Wallenstein GV (1994) A model of the electrophysiological properties of nucleus reticularis thalami neurons. Biophys $\mathrm{J}$ 66:978-988.

Wang XJ, Rinzel J (1992) Alternating and synchronous rhythms in reciprocally inhibitory model neurons. Neural Comput 4:84-97.

Wang XJ, Rinzel J (1993) Spindle rhythmicity in the reticularis thalami nucleus: synchronization among inhibitory neurons. Neuroscience 53:899-904.

Warren RA, Agmon A, Jones EG (1994) Oscillatory synaptic interactions between ventroposterior and reticular neurons in mouse thalamus in vitro. J Neurophysiol 72:1993-2003.

Yarom Y (1991) Rhythmogenesis in a hybrid system: interconnecting an olivary neuron to an analog network of coupled oscillators. Neuroscience 44:263-275.

Yen CT, Conley M, Hendry SH, Jones EG (1985) The morphology of physiologically identified GABAergic neurons in the somatic sensory part of the thalamic reticular nucleus in the cat. J Neurosci 5:2254-2268. 